\title{
AN ANALYSIS OF FACTORS AFFECTING THE OXYGEN CONSUMPTION OF THE ISOPOD LIGIA OCEANICA ${ }^{1}$
}

\author{
R. C. NEWELL, A. ROY, AND K. B. ARMITAGE \\ Institute of Biology, University of Odense, 5000 Odense, Denmark ; ${ }^{2}$ Départment des \\ Sciences Biologiques, Université de Montréal, Montréal 101 Québec $^{3}$ and Division \\ of Biological Sciences, University of Kansas, Lawrence, Kansas 66045
}

(Accepted 12/17/75)

\begin{abstract}
A multiple-regression equation was derived in which the statistical significance of the effects of six independent variables on metabolic rate could be arranged in the following order: exposure temperature, body weight, starvation period, feeding period, acclimation temperature, and percentage of lipids. Two multiple-regression equations were required to express the metabolism of Ligia oceanica without loss of accuracy when reapplied to the individual experimental data. One equation accounted for $84 \%$ of the variation of metabolism in animals acclimated to 5 or $12 \mathrm{C}$; the second accounted for $85 \%$ of the variation of metabolism in animals acclimated to 18 or $26 \mathrm{C}$. The rate:temperature curve for aerobic metabolism was sigmoid. A region of reduced temperature sensitivity occurred at intermediate exposure temperatures. Thermal acclimation had little effect on the level of metabolism of well-fed Ligia. The maximum metabolic rate shifted from $27.6 \mathrm{C}$ in fed animals acclimated at $5 \mathrm{C}$ to $28.2 \mathrm{C}$ in those acclimated at $12 \mathrm{C}$, to $33.1 \mathrm{C}$ in those acclimated at $18 \mathrm{C}$, and to $33.4 \mathrm{C}$ in those acclimated at $26 \mathrm{C}$. The region of reduced temperature sensitivity shifted from 15-25 C at low acclimation temperatures to $20-35 \mathrm{C}$ at high acclimation temperatures. The effects of starvation on oxygen consumption are controlled by body size, duration of starvation, and acclimation temperature. Metabolism is suppressed in small animals sooner than large ones at each acclimation temperature; high acclimation temperatures enhance the onset and magnitude of such effects. Exposure temperature and the period of starvation influenced the effect of body size on metabolism.
\end{abstract}

\section{INTRODUCTION}

The influence of environmental and endogenous factors on the aerobic metabolism of intertidal invertebrates has been widely reported in the literature (for review, see Newell 1973a, 1973b).

\footnotetext{
1 This work was supported by equipment and travel grants to R.C.N. from the Royal Society of London and the Science Research Council, and to A.R. by the National Research Council of Canada. By a sabbatical leave and by a travel grant from the University of Kansas, K.B.A. was supported from the Johnson Fund of the American Philosophical Society. The data analysis was carried out at the Université de Montréal. We are grateful to the director of the Centre de calcul for extensive facilities provided there and to Mme Roy for her generous hospitality during the initial phases of the analytical work.

${ }^{2}$ Niels Bohr Alle.

${ }^{3}$ Case Postale 6128.
}

Environmental factors have included both long-term and short-term temperature stresses (Newell and Bayne 1973), salinity (Rao 1958; Duncan 1966; Klekowski and Duncan 1966), photoperiod (Dehnel 1958; Webb and Brown 1958; Roberts 1964, 1967; Unglaub Silverthorn 1973), and oxygen availability (for review, see Mangum and Van Winkle 1973). Among the endogenous factors, the most widely studied has been the effect of body size (Zeuthen 1953, Hemmingsen 1960), although there are now many instances where other factors such as activity (McFarland and Pickens 1965; Halcrow and Boyd 1967; Thompson and Bayne 1972; Bayne, Thompson, and Widdows 1973; Widdows 1973), nutritional conditions (Hagerman 1970; 
Thompson and Bayne 1972; Wallace 1972, 1973; Marsden, Newell, and Ahsanullah 1973) and stage in the reproductive cycle were important. Rhythmical changes in the rate of oxygen consumption (Ansell 1973; Aldrich 1975) may also complicate the interpretation of such factors. Finally, the excitation due to disturbance may induce elevated rates of oxygen consumption even in the absence of locomotory activity in some crustaceans (Newell, Wieser, and Pye 1974; Aldrich 1975), as in many vertebrates.

It is thus apparent that the results of experimental studies on the oxygen consumption of intact organisms may contrast sharply with one another and will largely reflect the particular combination of conditions which have been incorporated into the experimental procedure. Following starvation of the crab Carcinus maenas, for example, the oxygen consumption of small specimens is suppressed more than in large crabs (Marsden et al. 1973). Presumably this is because the higher weight-specific metabolic rate of small crabs causes a utilization of the metabolic reserves more quickly than in large ones. Again, the temperature at which the animals are starved might be expected to influence the rate of depletion of the metabolic reserves and hence affect the onset of such reduced rates of oxygen consumption. Few generalizations can therefore be made on the influence of starvation on aerobic metabolism unless both starvation temperature and body size have been systematically taken into account.

Inspection of the literature on the oxygen consumption of invertebrates suggests that there may be other examples of such interactions between environmental and endogenous factors. In the gastropod Littorina littorea, for example, there is an interaction between body size and exposure temperature in controlling the level of oxygen consumption, that of small animals being less affected by acute temperature changes than large ones (Newell and Roy 1973); similar effects have been noticed in Carcinus (Marsden et al. 1973). Data cited for the amphipod Talorchestia and the sand crab Emerita (Rao and Bullock 1954), for the amphipod Orchomonella (Armitage 1962), for Uca (Vernberg 1959), and for Arion (Roy 1969) also suggest that body size influences the relationship between oxygen consumption and exposure temperature. Discussion of the specific effect of temperature on the metabolism of such animals may be misleading unless details of body size and nutritional state are reported.

We therefore considered it important to make an integrated study of the influence of a variety of both environmental and endogenous factors on the oxygen consumption of invertebrates, in which a wide variety of variables were systematically taken into account. In the first instance, we analyzed the interaction between seasonal and other factors controlling the aerobic metabolism of Littorina (Newell and Roy 1973; see also Newell 1975). Since then it has become evident that other factors, including nutritional level, should be incorporated into the analysis. Accordingly, the second phase of our work was to study the effects on metabolism of acclimation temperature, short-term exposure temperature, starvation time, lipid content, acclimation time, and body size. The isopod Ligia oceanica was selected because it lives well in the laboratory and was available in a wide variety of sizes. There is also some information in the literature on its rate of oxygen consumption in air (Ellenby 1951; Ellenby and Evans 1956; Remmert 1967; Wieser 1972), suggesting that the 
metabolic energy requirements are entirely met by aerial gas exchange. This has distinct advantages experimentally since it is not necessary to shake the respirometer vessels, as it is in organisms in a volumetric respirometer which respire aquatically. The animals also remain motionless for long periods in moist aerial conditions, so that measurements could be made without introducing activity as a variable. Each of the experimental variables and various combinations of them could then be related quantitatively to the oxygen consumption of quiescent Ligia using the multiple-regression technique described elsewhere (Newell and Roy 1973).

Although we have not been able to incorporate activity or seasonal factors into the equation at this stage, the results are generally similar to those obtained on Littorina. Comparative studies on other organisms should be worthwhile to determine whether similar multipleregression equations can be applied to organisms from different environmental conditions. Then it will be possible to make meaningful predictions of the effects of complex combinations of environmental factors on aerobic metabolism under natural conditions.

\section{MATERIAL AND METHODS}

COLLECTION AND CULTURE OF ANIMALS

Specimens of Ligia oceanica were collected from beneath stones and among grass roots on the upper shore at Wembury, Devon, U.K., on January 25, 1973, when the air temperature was approximately $7 \mathrm{C}$. Large numbers of all sizes were common in this locality, and after collection they were transported to the laboratory in plastic boxes containing moist algae. They were then placed at $12 \mathrm{C}$ in plastic boxes lined with filter paper moistened with seawater and containing food consisting of fresh pear, which was eaten by all sizes of animals. After 5 days, a group of approximately 200 animals was separated from the main culture and divided into two subgroups, one of which was presented with excess food and the other starved. Both subgroups were placed at $5 \mathrm{C}$ under a light regime of $12 \mathrm{~h}$ light and $12 \mathrm{~h}$ darkness, synchronized approximately with the natural photoperiod. At the same time, another group of 200 animals was removed from the main culture, and both starved and fed subgroups were placed at $12 \mathrm{C}$ under a 12-h light:dark regime (fig. 1).

\section{EXPERIMENTAL METHODS}

Group 1 animals.-On the following day, the rate of oxygen consumption of 18 different-sized animals from the stock culture was measured in a Gilson differential respirometer (Model G.R. 20) at a variety of different exposure temperatures between 5 and $30 \mathrm{C}$. Two

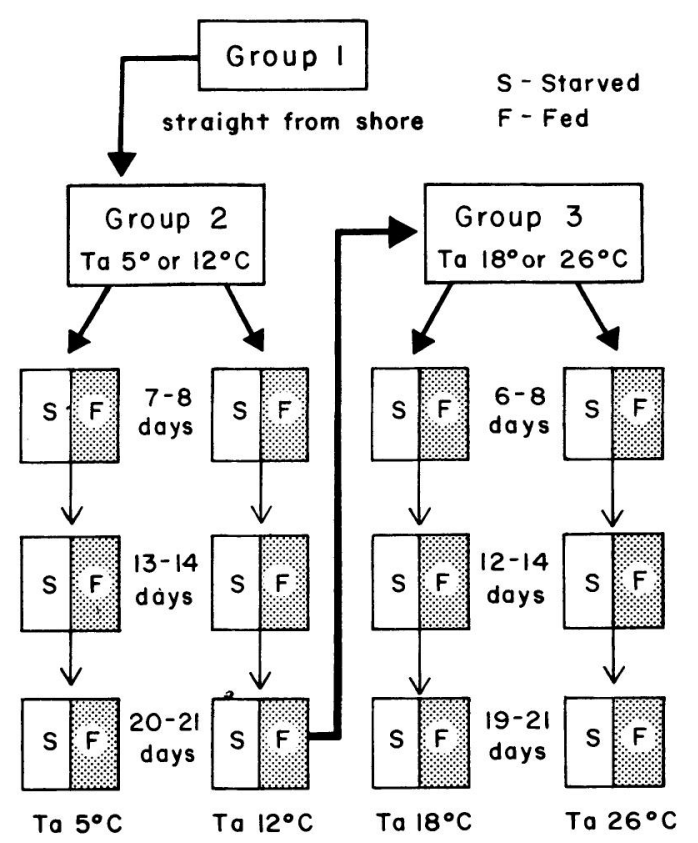

FIG. 1.-Flowchart of the experimental design of laboratory acclimation of fed and starved Ligia oceanica. 
flasks containing a filter paper moistened with pasteurized seawater and with $15 \%$ $\mathrm{KOH}$ in a side tube were used as controls. The same individuals were used for all exposure temperatures, which were normally presented in the sequence $5,15,10,25,20$, and $30 \mathrm{C}$ to prevent short-term acclimation occurring during the experimental period. The animals were placed in $10-\mathrm{ml}$ flasks with a side tube containing $0.5 \mathrm{ml} 15 \% \mathrm{KOH}$. Each flask also contained a horizontal scroll of filter paper moistened with pasteurized seawater and placed so that the Ligia could remain in air on the paper. Under these conditions, the animals remained motionless throughout the experiment. They were left for $30 \mathrm{~min}$ to equilibrate to the temperature of the water bath, after which readings were made for 30 min at 3-min intervals. The vessels were carefully left undisturbed for the duration of the experiment. Then the temperature was altered and, after a further equilibration period of $30 \mathrm{~min}$, a new set of readings was taken. At the end of the experiment, the animals were removed from the flasks, dried to constant weight at $60 \mathrm{C}$, and weighed. The dried specimens were then placed in stoppered vials and their total lipid content measured as described elsewhere (Armitage, Newell, and Roy 1976). These animals are referred to as "group 1" specimens and form a reference from which the acclimatory responses and starvation effects can be derived.

Group 2 animals.-After 7 days, 18 specimens of the Ligia which had been kept at $5 \mathrm{C}$ with food were placed in the respirometer and their oxygen consumption measured at temperatures between 5 and 35 C. During the equilibration periods, measurements were made in the same sequence on 17 of the starved animals which had meanwhile been placed in a second respirometer. In this way, an alternating series of measurements of the rate of oxygen consumption at exposure temperatures of $5,15,10$, $25,20,30$, and $35 \mathrm{C}$ was completed on both starved and fed subgroups in 1 day. On the following day (i.e., after 8 days of acclimation), identical measurements were made on animals which had been held at 12 C. After 13 days, a further group of starved and fed animals were removed from the culture at $5 \mathrm{C}$ and their oxygen consumption measured; the same was carried out after 14 days on the animals maintained at $12 \mathrm{C}$. Finally, measurements were made after 20 days on the starved and fed animals acclimated to $5 \mathrm{C}$ and after 21 days on those which had been acclimated to $12 \mathrm{C}$. In this way, data were collected on the effect of starvation time, body size, lipid content, acclimation time, acclimation temperature, and exposure temperature on the metabolism of Ligia. The animals from which these data were obtained are referred to as "group 2" specimens in the results.

Group 3 animals.-These animals were studied in the same way as group 2 animals, except that they were acclimated at $18 \mathrm{C}$ and $26 \mathrm{C}$; and respiration was measured on starved and fed animals at a series of exposure temperatures after 8,14 , and 21 days at $18 \mathrm{C}$ and 6 , 12 , and 19 days at $26 \mathrm{C}$ (fig. 1). These data, the starting point of which was a measurement on animals maintained and fed in the stock culture at $12 \mathrm{C}$ for $3 \mathrm{wk}$, are referred to as "group 3" in the results. In all cases, the oxygen consumption was expressed as $\mu \mathrm{l} \mathrm{O}_{2} / \mathrm{h}$ and both total dry weight and lipid-free dry weight (g) were recorded.

\section{ANALYSIS OF DATA}

GENERAL PROCEDURE

The data obtained from the experiments described above were related to 
the following seven variables: $\log$ dry body weight in milligrams $(L d)$, exposure temperature $(T e)$, acclimation temperature $(T a)$, feeding period in days $(F d)$, starving period in days $(S d)$, percentage of lipids $(P l)$, and log metabolic rate $\left(\mathrm{mm}^{3}\right.$ oxygen/h) $(\mathrm{Lm})$. The first six variables are considered here as independent variables affecting the rate of oxygen consumption, which is treated as the dependent variable. Feeding period and starving period also reflect a component of the acclimation period. For example, an animal fed and acclimated for 7 days to a particular temperature was recorded as having experienced a $F d$ of 7 days and a $S d$ of 0 days. Conversely, an animal starved during acclimation for 7 days was recorded as having a $F d$ of 0 days and a $S d$ of 7 days. Lipid content was accounted for as percentage of lipids, rather than lipid weight or $\log$ lipid weight, so that this variable could be rendered more independent of total dry body weight in the statistical analysis.

In all, 3,130 observations were obtained on the oxygen consumption of Ligia oceanica in relation to the six variables defined above. These data were distributed into 181 subgroups, within each of which $T e, T a, F d$, and $S d$ had fixed values. As mentioned, 17 or 18 different-sized animals were used in the experiments (an average of 17.3 for the whole of the data), so that the relation of metabolic rate to body size could be evaluated as a simple regression line based on the well-known equation

$$
L m=a+b \cdot L d
$$

the validity of which has been previously discussed by Newell and Roy (1973). The 181 simple-regression lines obtained are shown graphically in figures $2-6{ }^{4}$

The influence $T e$, ranging from 5 to $40 \mathrm{C}$, on $L m$ is more important in the present data than that of $L d$, which ranges from approximately 1.2 to 2.2 . Because the oxygen consumption of each animal was determined at six to eight different temperatures, the influence of $T e$ is very clearly defined in the data. Accordingly, our next step in the analysis was to merge the data from the 181 small subunits into 25 intermediary subgroups within which $T a, F d$, and $S d$ had a fixed value and where the simultaneous effects of $L d$ and $T e$ could be evaluated. The first of such intermediary subgroups is for animals measured soon after collection from the shore (i.e., at "acclimation time 0 "). Then there are six intermediary subgroups for each of the four Tas used. These six consist of starved and fed animals, each considered after three different acclimation periods.

We have adopted the mathematical model proposed by McLaren (1963) describing the relationship between metabolic rate $(M)$ and $T e$ :

$$
M=\alpha b^{T e}
$$

which can be conveniently transformed for statistical evaluation into a semilogarithmic equation:

$$
L m=a+b \cdot T e
$$

where $a=\log \alpha$. This equation is valid for relatively short intervals of $T e$, within which the relation of $L m$ to $T e$ can be considered as rectilinear. However, when nearly the whole range of tolerable $T e$ s is used, as in the present case, the relation becomes definitely curvilinear. When plotting the raw data

${ }^{4}$ Tables containing the numerical values of the individual 181 regression lines with their correlation coefficients have been added as an appendix in manuscript copies of this paper kept at the Bibliothéque de biologie, département des sciences biologiques, Université de Montréal, from which they can be consulted through the regular interlibrary loan procedure. 


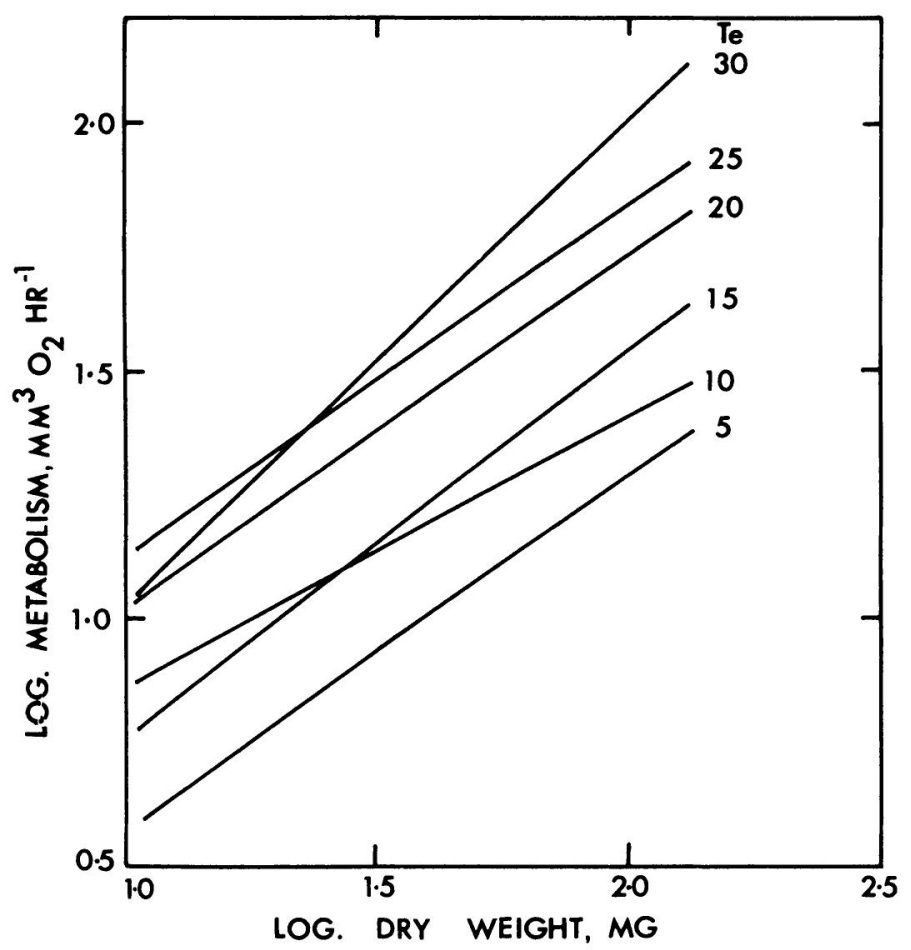

FIG. 2.-Simple-regression lines obtained at each experimental temperature when $\mathrm{Lm}$ of Ligia oceanica is plotted as a function of $L d$, directly after collection from the shore on January 25,1973 . These are "group 1 data" prior to laboratory acclimation. The lengths of the lines are drawn according to the range of body weights in the group of data.

for $L m$ of Ligia as a function of Te within each subgroup (e.g., fig. 7), most of the individual rates, each corresponding to one particular specimen, are extremely complex, showing peaks of oxygen consumption and zones of reduced rates. Much the same pattern emerges when the level of the simple-regression lines shown in figures 3-6 is plotted as a function of $T e$ (fig. 8). Because the simpleregression lines are not parallel, the levels used in figure 8 were evaluated at the common $L d$ value of 1.7 , which is close to the general mean of $L d$ values in the whole data. Rate:temperature curves of this general form estimated from data for individual rates and from simple-regression lines are not uncommon in the literature (see Sandison 1967; Barnes and Barnes 1969; Newell 1975) and require a fifth-degree polynomial for correct mathematical representation:

$$
\begin{aligned}
& L m=a+b_{1} T e+b_{2} T e^{2} \\
& +b_{3} T e^{3}+b_{4} T e^{4}+b_{5} T e^{5} .
\end{aligned}
$$

In order to account for the varying body sizes within the 25 subgroups, equations (1) and (4) were combined to give

$$
\begin{aligned}
& L m=a+b_{1} L d+b_{2} T e+b_{3} T e^{2} \\
& +b_{4} T e^{3}+b_{5} T e^{4}+b_{6} T e^{5} .
\end{aligned}
$$

This equation is a generalized one which satisfactorily accounts for the variation of the $\log$ metabolism when all the data are pooled into one group. However, when applied to individual subgroups of data where the number of $T e s$ is small, curves were predicted from 
equation (5), which, although mathe- check the validity of the multiplematically valid, often showed very low regression equations, and in this case interpolated values not supported by it was necessary to omit the term $b_{2} T e$ actual data between $T e$ values of 5 and from the general multiple-regression $10 \mathrm{C}$ or between 10 and $15 \mathrm{C}$. Through- equation (5). This yields

out the analysis we have taken the $L m=a+b_{1} L d+b_{2} T e^{2}+b_{3} T e^{3}$ original data as a reference point to

$$
+b_{4} T e^{4}+b_{5} T e^{5} \text {. }
$$

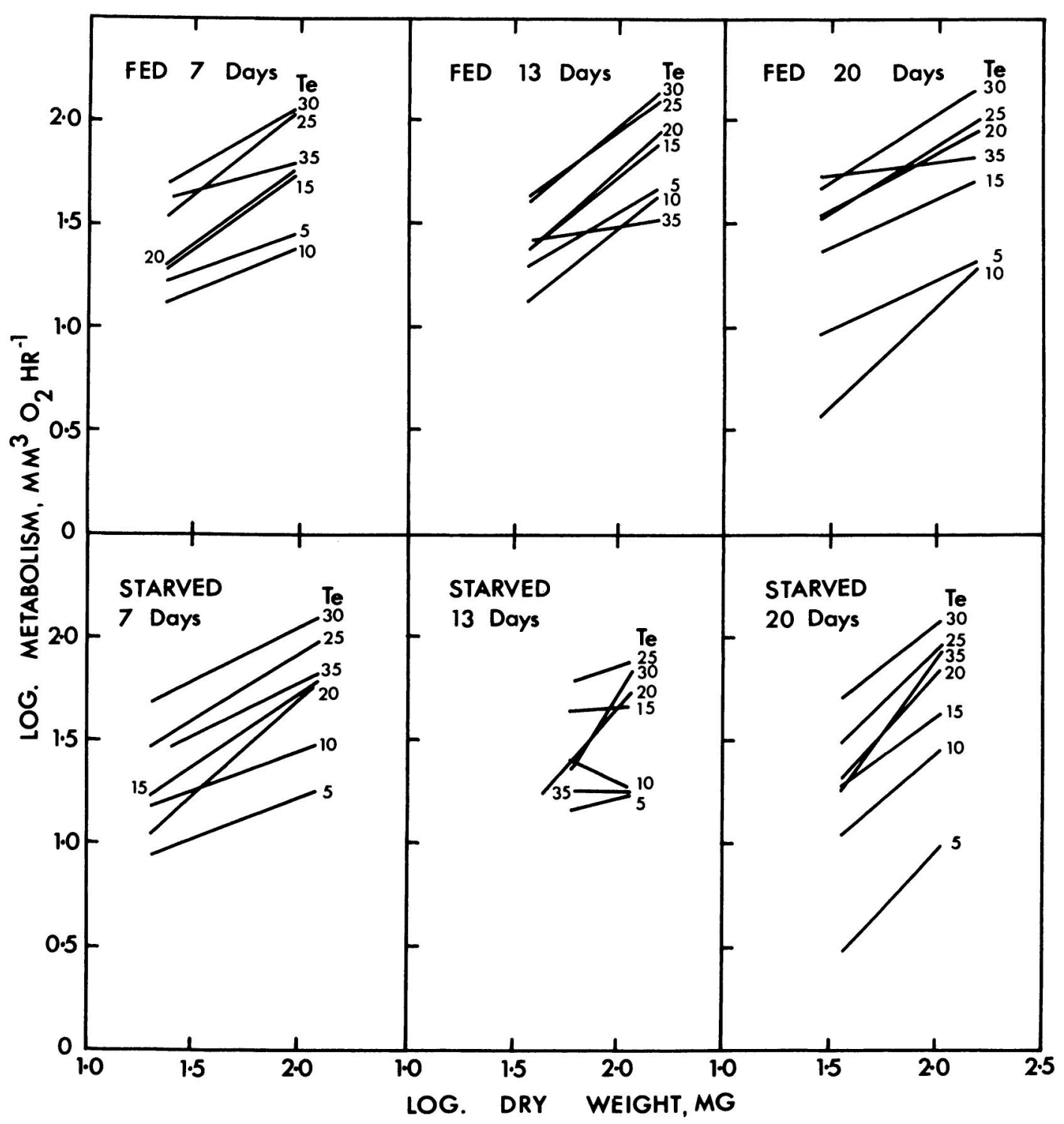

FIG. 3.-Simple-regression lines obtained at each $T e$ when $L m$ of Ligia oceanica is plotted as a function of $L d$, following laboratory acclimation at $5 \mathrm{C}(T a 5)$ for 7-20 days. The lengths of the lines are drawn according to the range of body weights in each subgroup of data. 
The effects predicted by equation (6) of $T e$ on the aerobic metabolism of $L$. oceanica directly after collection from the shore are shown in figure 9, while similar curves for starved and fed animals after different periods of acclimation to a variety of temperatures are shown in figure 10.
We consider that the 24 multiple regressions which yield the family of curves illustrated in figure 11 show definite trends from one subgroup to the other, although the trends themselves are subject to the normal and expected intergroup random variation. In order to check the consistency of such trends

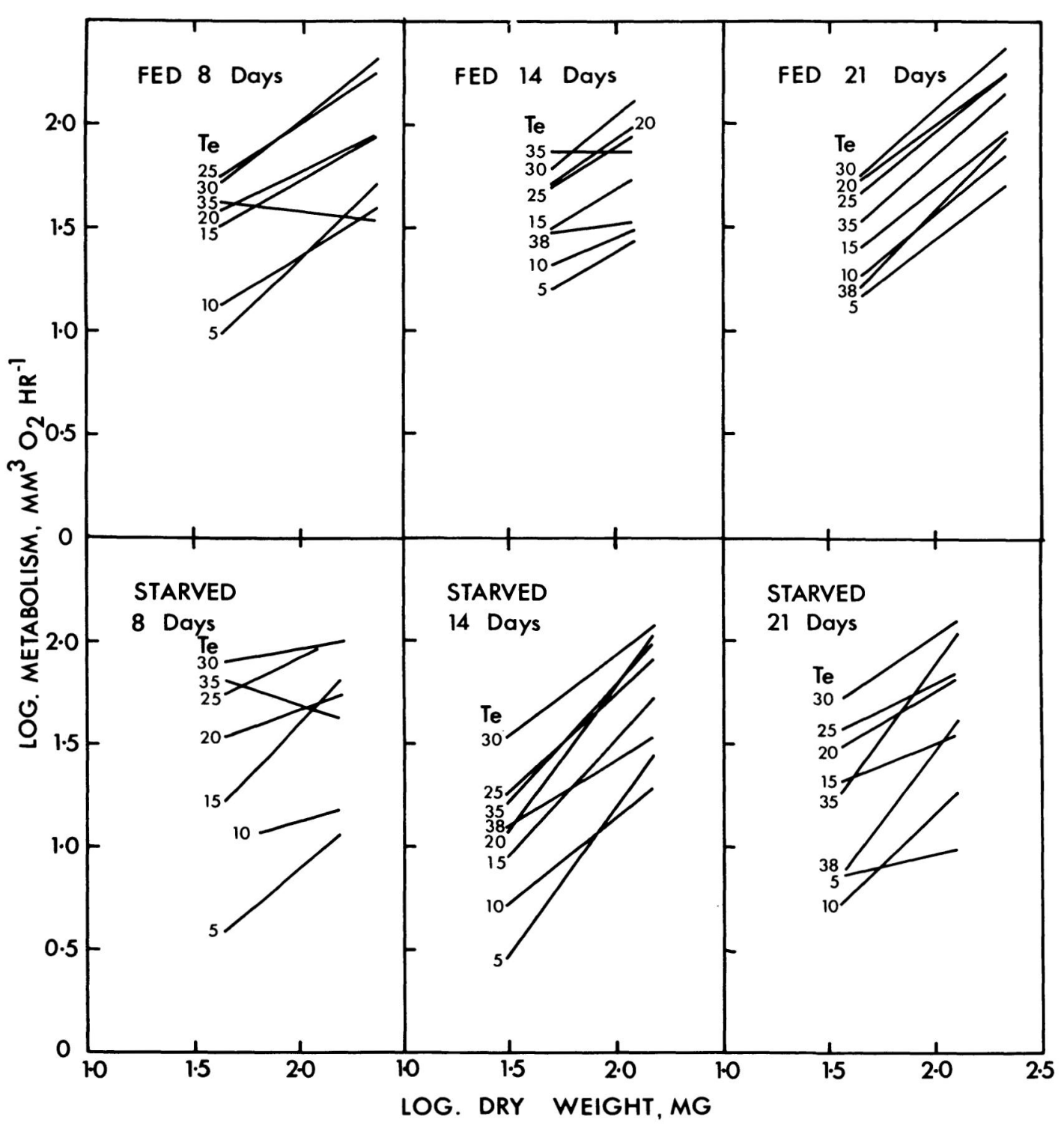

Fig. 4.--Simple-regression lines obtained at each $T e$ when $\mathrm{Lm}$ of Ligia oceanica is plotted as a function of $L d$, following laboratory acclimation at $12 \mathrm{C}(T a 12)$ for 8-21 days. The lengths of the lines are drawn according to the range of body weights in each subgroup of data. 
and also to clarify the general influence of $T a, F d, S d$, and $P l$, the 24 subgroups illustrated in figure 11 were successively merged into eight, four, and two subgroups of larger and larger extension, by adding appropriate terms to the model represented by equation (5). This equation was used to evaluate the data in each of the 25 subgroups, using a computer program, REMUL. The independent variables were introduced one by one, tested for statistical significance, and either kept, replaced by another one, or removed (see Effroymson 1960). This procedure is similar to that which we used in an analysis of data for Littorina

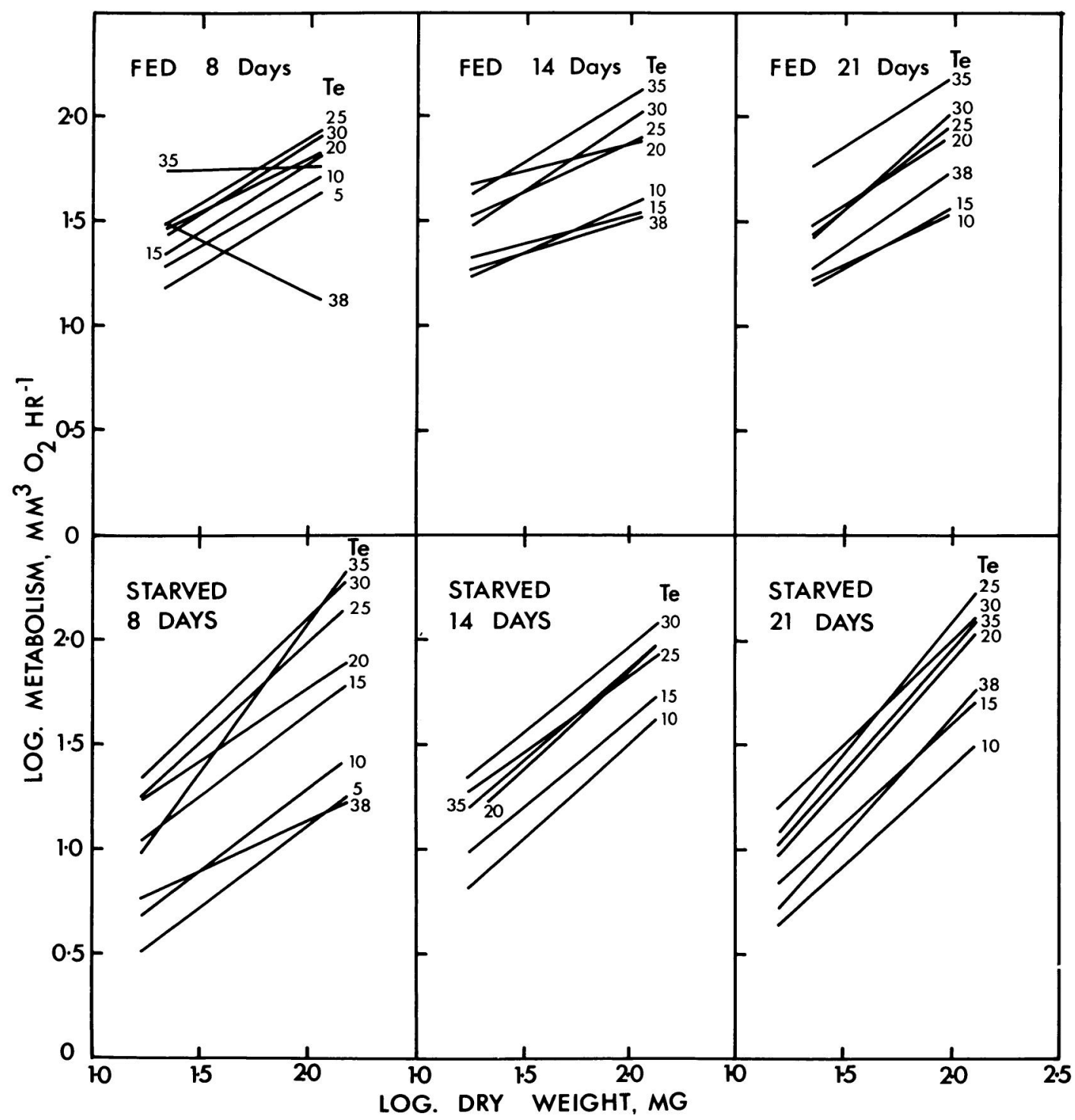

Fig. 5.--Simple-regression lines obtained at each $T e$ when $L m$ of Ligia oceanica is plotted as a function of $L d$, following laboratory acclimation at $18 \mathrm{C}(\mathrm{Ta} 18)$ for 8-21 days. The lengths of the lines are drawn according to the range of body weights in each subgroup of data. 
and is designed to give the most probable mathematical representation of the data in which all the partial-regression coefficients are statistically significant. After the final numerical results are obtained from the equation, the program can also produce a series of graphical representations of the relation of each factor (or raw independent variable) to the dependent variable when the other factors have a defined value within their experimental ranges.

The complexity of the $L m: T e$ curves, together with the fact that $T e$ has only nine different values in all the data, made the optimal determination of the

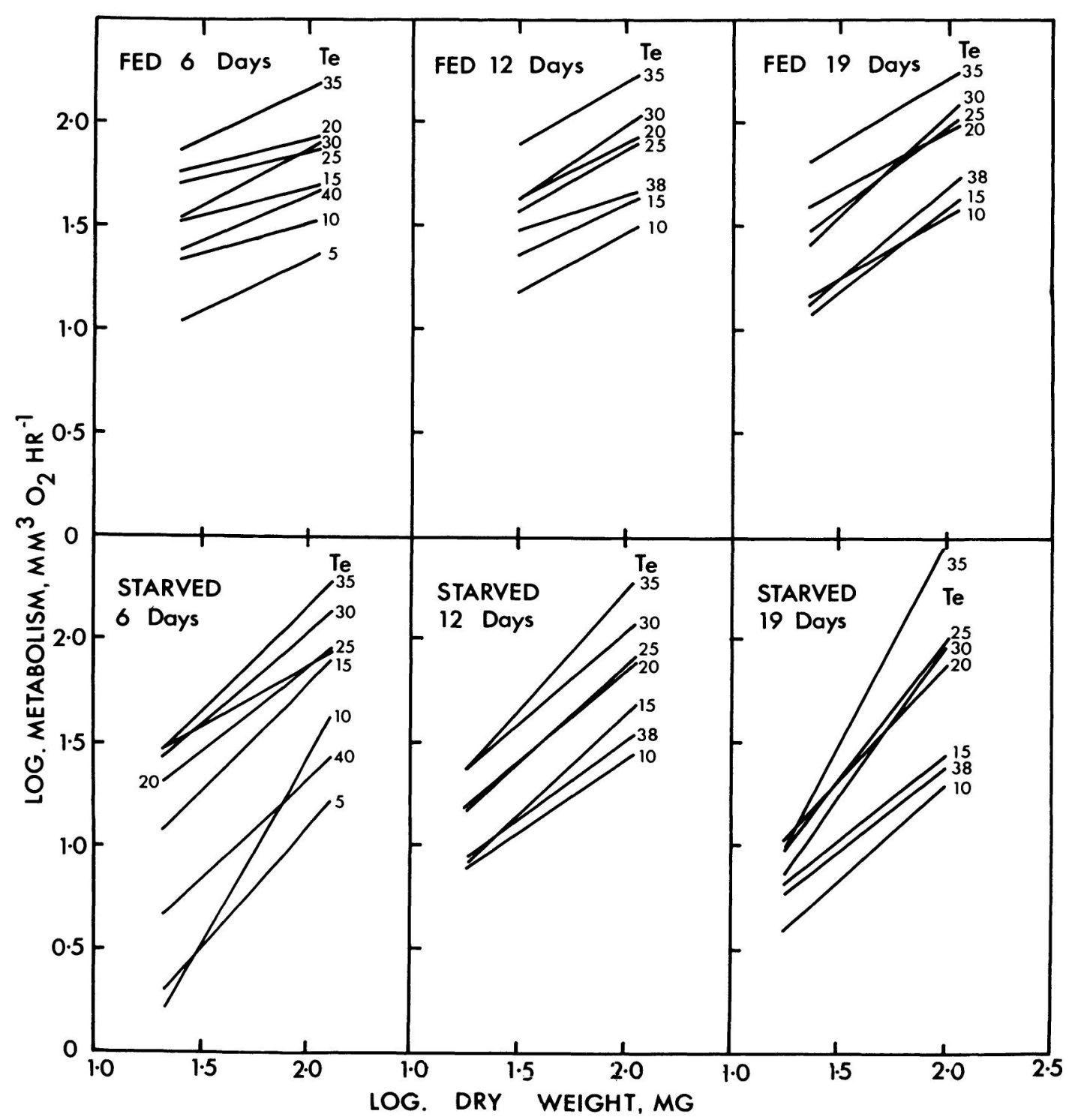

FIG. 6.-Simple-regression lines obtained at each $T e$ when $L m$ of Ligia oceanica is plotted as a function of $L d$, following laboratory acclimation at $26 \mathrm{C}(T a 26)$ for 6-19 days. The lengths of the lines are drawn according to the range of body weights in each subgroup of data. 

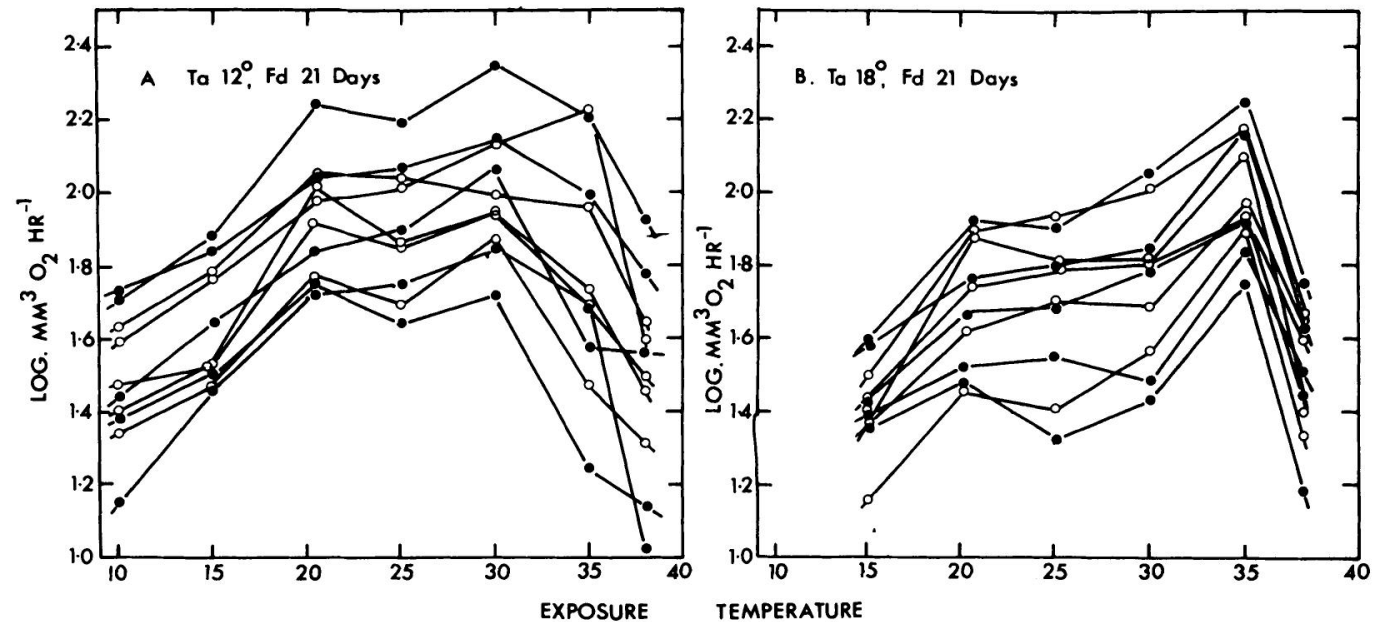

Fig. 7.- Responses of representative individual rates of $L m$ plotted against $T e$. These curves form a reference set of data with which the multiple-regression models were compared.

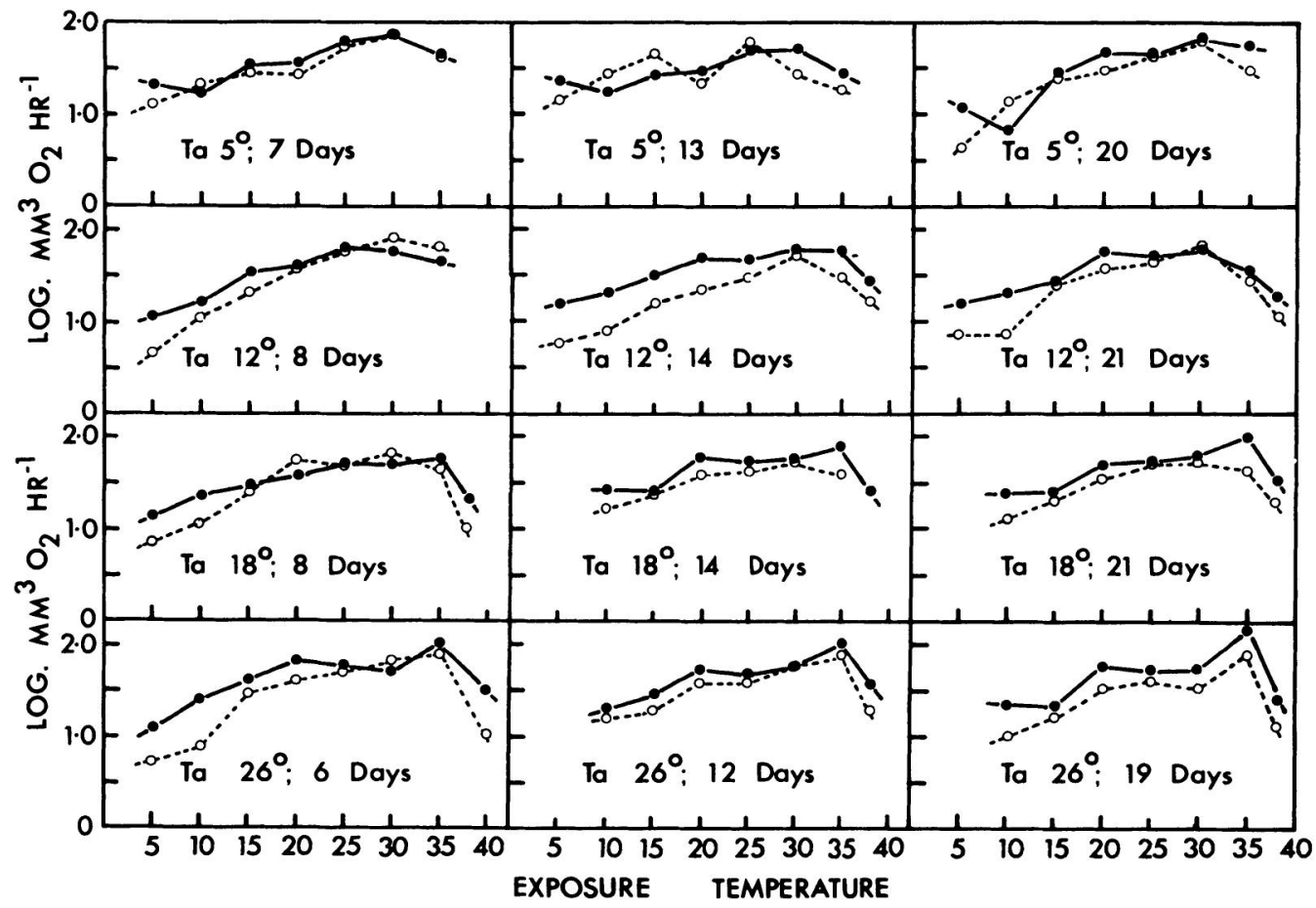

FIG. 8.-Effect of temperature on the $L m$ level of a hypothetical specimen of Ligia of $50 \mathrm{mg}$ dry wt ( $L d$ 1.7) held at various $T a$ s for 1-3 wk. Continuous lines indicate fed animals, broken lines indicate starved animals. Curves are obtained from the level of the simple-regression lines shown in figs. 3-6. 


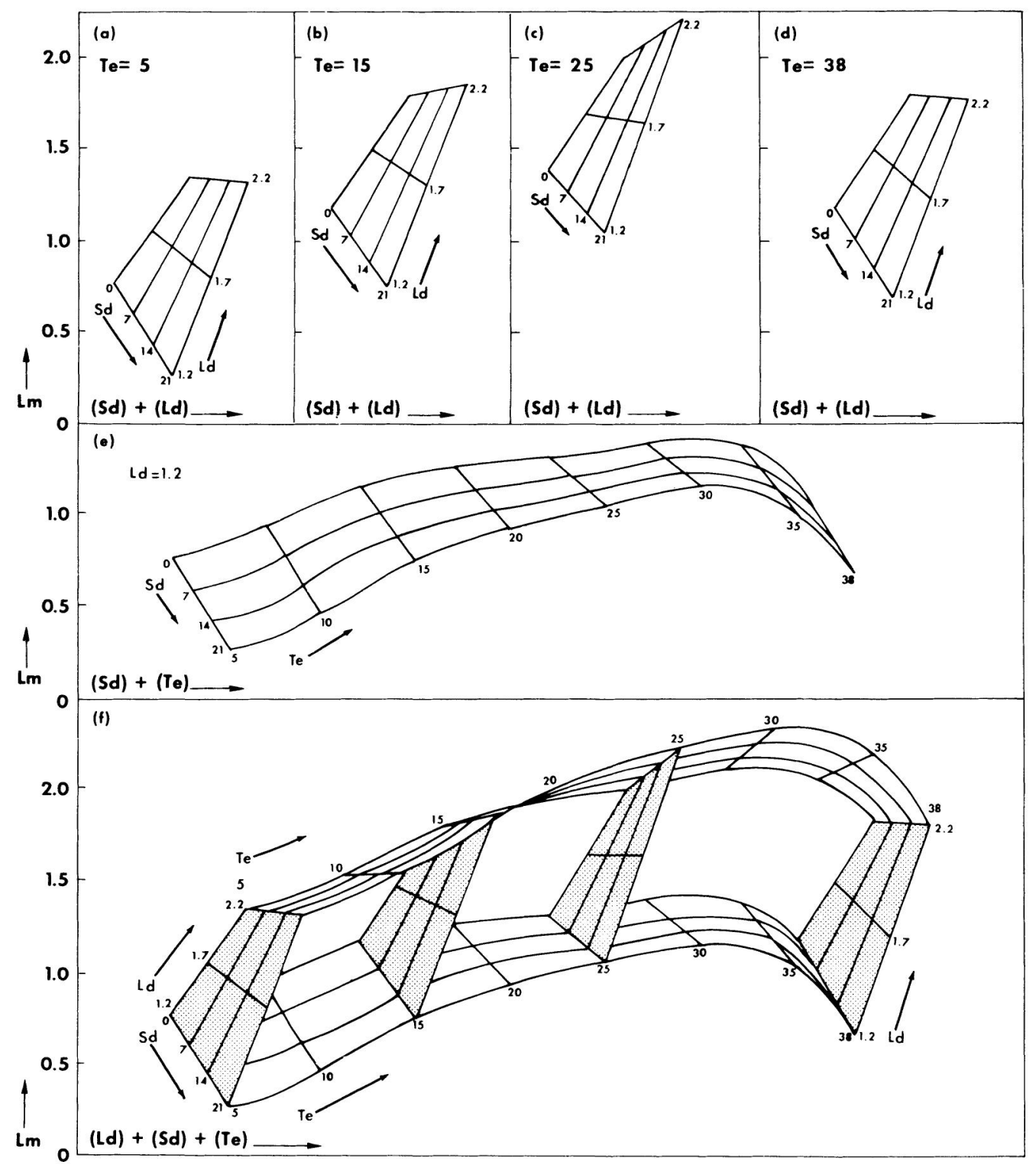

FIG. 9.-Graphs illustrating the construction of a four-dimensional diagram to illustrate multiple-regression eq. (8). $a-d$, Flattened three-dimensional representations of $L m$ as a function of $L d$ and $S d$, when $P l$ has a fixed value of $25, T a$ is fixed at $18, F d$ is fixed at 0 , and $T e$ has fixed values of $5,15,25$, or 38 . $e$, Flattened three-dimensional representation of $L m$ as a function of $T e$ and $S d$ when $P l, T a$, and $F d$ have fixed values as above, and $L d$ is fixed at 1.2. $f$, Four-dimensional representation of $L m$ as a function of $L d$, $S d$, and $T e$ obtained by assembling four $L m: S d: L d$ and two $L m: S d: T e$ panels along the $L m: S d$ lines they have in common. 
successive multiple regressions a somewhat difficult problem. Indeed, it was not feasible to include in one mathematical expression all the curvilinearity and interaction terms suggested by a careful examination of figures $3-6$ and 11. At each step of the merging procedure we again returned to these figures, which can be considered as representing the unbiased raw data. In this way we could assess the accuracy of the different versions obtained, which were also judged according to their probability level.

Our ultimate aim of representing all of the 3,130 data by one multipleregression equation describing the responses of the metabolism of L. oceanica to a variety of environmental and endogenous factors thus was not achieved in this study, because many of the specific features of the individual results for each acclimation regime which we considered important were eliminated by the analysis. Possibly cold-acclimated ( $T a=5$ or $12 \mathrm{C}$ ) Ligia have qualitatively different metabolic pathways from those of warm-acclimated ( $T a=18$ or 26 C) animals. This difference would explain why a generalized equation generated from all the data did not predict curves which adequately resemble the raw data from each group of animals. Thus, the metabolism of Ligia is best described by two basic equations (table 1) which can be applied to the animals acclimated to 5 and $12 \mathrm{C}$ and to those acclimated to 18 and $26 \mathrm{C}$, respectively.

The mathematical model finally selected for these two equations is not the only possible one. Several other alternatives were tried; the model retained appeared to us to represent best all the data. The six factors affecting metabolic rate in this investigation may be arranged in the order of their overall statistical significance: $T e, L d, S d, F d$,

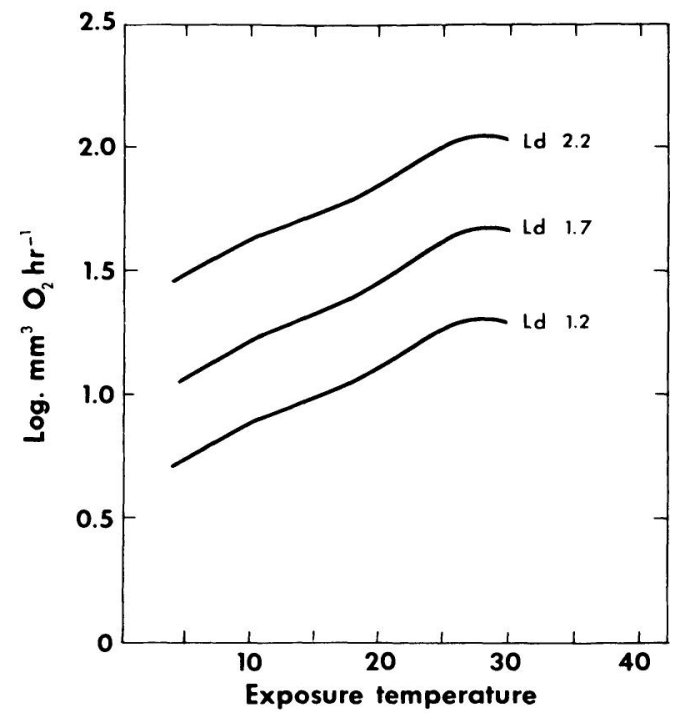

FIG. 10.-Effects of $T e$ on $L m$ for hypothetical specimens of Ligia oceanica of $16 \mathrm{mg}$ (Ld 1.2), 50 $\mathrm{mg}(L d 1.7)$, and $160 \mathrm{mg}$ ( $L d 2.2$ ) dry tissue wt. Data predicted for group 1 Ligia.

$T a, P l$. Alternative mathematical models altered only slightly the estimation of the general influence of $T e$ and $L d$ but gave somewhat different (but not contradictory) patterns for the influence of the other variables.

\section{GRAPHICAL REPRESENTATION METHOD}

The multiple-regression equations (see table 1) are the equivalent of abstract bodies located in a seven-dimensional space which do not lend themselves to graphical representation. However, the equivalent of cross sections can be made through the multidimensional space to obtain simplified equations of a lower level of complexity. For example, if the symbol $P l$ of equation (8) (table 1) is replaced by the numerical value 25 and algebraic simplification is applied to the result, a simplified equation for the influence of $L d, T e, F d, S d$, and $L m$ for animals having a lipid content of $25 \%$ is obtained. The new simplified equation corresponds to a six-dimensional space. If one cuts through the six-dimensional 


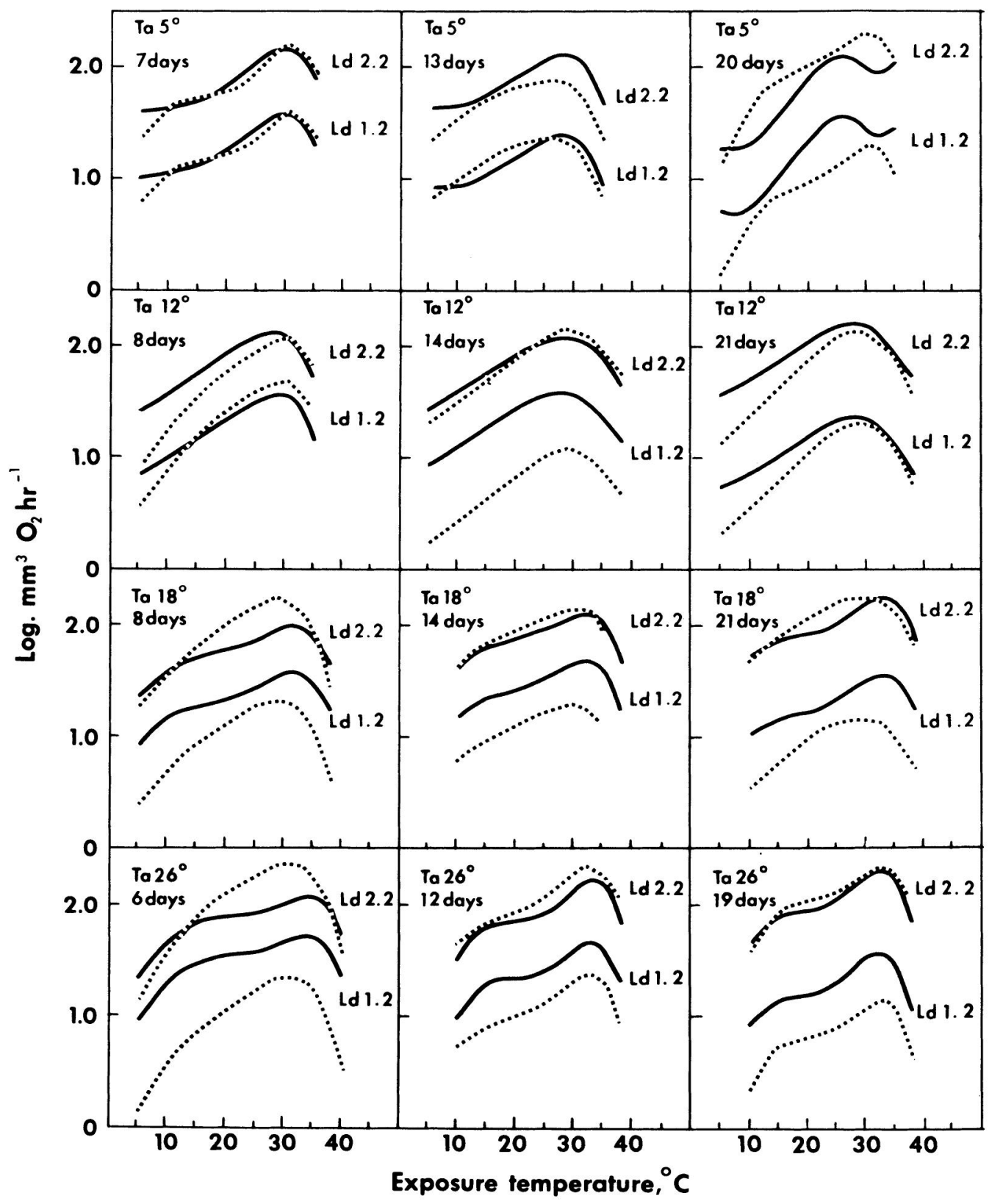

FIG. 11.-Rate: temperature curves for $L m$ of quiescent Ligia oceanica in response to laboratory acclimation. Continuous lines refer to data for fed animals and broken lines to starved specimens. Based on eq. (6). 
space by considering only the starved animals acclimated to $18 \mathrm{C}, F d$ will be replaced by 0 and $T a$ by 18 , and a new simplified equation combining the influence of $L d, T e$, and $S d$ on $L m$ will be obtained. The resulting four-dimensional space is represented graphically in figure 9.

If the four-dimensional space is reduced to a three-dimensional space by giving a fixed numerical value to $T e$, a simplified equation showing the effects of $L d$ and $S d$ on $L m$ is obtained. Equations of this kind generally are represented as an inclined surface enclosed in a cubic support or box. Finney (1952, pp. 105, 109), using earlier suggestions by Richards (1941), showed that the inclined surface can be replaced, without any loss of visual meaning, by a quadrilateral figure containing two familes of intercrossing lines drawn on a flat twodimensional space. The dependent variable is displayed along the ordinate, as usual, while the abscissa value of each of the intersection points within the quadrilateral corresponds to the sum of the graphical scale values of the two independent variables. The individual graphical scales are shown along two sides of the quadrilateral (see also Fredette, Planté, and Roy 1967).

Such flattened representations of the effects of $S d$ and $L d$ on $L m$ at a series of $T e$ s are presented in figure $9 a-d$. The four drawings may be viewed either as flat quadrilateral figures or as inclined surfaces in a three-dimensional space,

TABLE 1

MULTIPLE-REGRESSION EQUATIONS REPRESENTING $L m$ BY "LIGIA OCEANICA" AS A FUNCTION OF $L d, T e, T a, F d, S d$, AND $P l$

\begin{tabular}{|c|c|c|}
\hline \multirow[b]{2}{*}{$\begin{array}{l}\text { Complete Mathemati- } \\
\text { Cal Model }\end{array}$} & \multicolumn{2}{|c|}{$\begin{array}{c}\text { Numerical Values of } a \text { and of Partial-Re- } \\
\text { gression Coefficients } b \text { AFter } \\
\text { Elminations }\end{array}$} \\
\hline & $\begin{array}{c}\text { Eq. (7) for Animals } \\
\text { Acclimated to } \\
5 \text { or } 12 \mathrm{Ca}^{\mathrm{a}}\end{array}$ & $\begin{array}{c}\text { Eq. (8) for Animals } \\
\text { Acclimated to } \\
18 \text { or } 26 \mathrm{Cb}^{\mathrm{b}}\end{array}$ \\
\hline 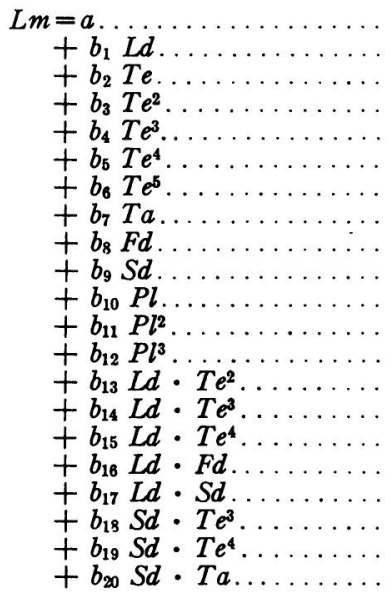 & $\begin{array}{c}+0.02399 \\
+0.6498 \\
+0.001484 \\
-0.00002394 \\
\ldots \\
\ldots \\
\ldots \\
-0.03205 \\
-0.01303 \\
+0.0004360 \\
-0.000003832 \\
+0.0003278 \\
-0.0000003767 \\
+0.002148 \\
+0.01291 \\
+0.000001800 \\
-0.00000004396 \\
-0.0003829\end{array}$ & $\begin{array}{l}+0.3776 \\
+0.5847 \\
-0.2017 \\
+0.03332 \\
-0.002032 \\
+0.00005399 \\
-0.0000005240 \\
+0.006341 \\
+0.01519 \\
-0.03850 \\
-0.003809 \\
+0.00009537 \\
\quad \ldots \\
+0.00002215 \\
-0.0000005735 \\
-0.007544 \\
+0.02285 \\
+0.000002272 \\
-0.00000005963 \\
-0.0007346\end{array}$ \\
\hline
\end{tabular}

Note.-Here and in subsequent tables, $L m$ represents $\log$ oxygen consumption in $\mathrm{mm}^{2} / \mathrm{h}, L d$ represents $\log$ dry weight, $T$ e represents exposure temperature, $T a$ represents acclimation temperature, $F d$ represents feeding period in days, $S d$ represents starvation period in days, and $P l$ represents percentage of lipids.

a $N$ observations covered by one equation: 1,625 ; multiple correlation coefficient: .8448 .

b $N$ observations covered by one equation: 1,649 ; multiple correlation coefficient: .8538 . 
even if the conventional cubic frame is not explicitly shown. Figure $9 e$ is another flattened representation of a three-dimensional relation, showing the curvilinear effect of $T e$ and the rectilinear effect of $S d$ on $L m$ in the same subgroup of the Ligia data, when $L d$ has a fixed value of 1.2. If the homologous graph for $L d 2.2$ is drawn, six panels are produced, four corresponding to $L d: S d: L m$ relations and two corresponding to $T e: S d: L m$ relations. Because the two series of panels have some $S d: L m$ lines in common, they can be assembled along those common lines (fig. 9f). Each component panel maintains its own symbolic meaning as previously defined, while the complete graph becomes a tangible representation of an abstract body located in four-dimensional space. The appearance of the figure with inclined walls and oddly bent floor and roof should assist the nonmathematician to localize the 43 individual lines that it contains and appreciate the symbolic meaning each keeps as if it were isolated as a two-variable relation.

A more complete description of this graphical method, giving rules for the selection of the appropriate graphical scales and showing applications to other types of equations, is being prepared by Roy.

\section{RESULTS AND DISCUSSION}

THE MULTIPLE-REGRESSION EQUATIONS

The final result of the statistical analysis consists of two multiple-regression equations, identified as (7) and (8), whose numerical values are listed and compared in table 1. Equation (7) is for group 2 animals acclimated to 5 or $12 \mathrm{C}$ and fed or starved from 1 to $3 \mathrm{wk}$ (fig. 1). The equation also includes the 108 observations on animals tested directly after collection from the shore and prior to acclimation. Of these, half were regarded as being acclimated to $5 \mathrm{C}$ at time 0 while the other half was considered as representing acclimation to $12 \mathrm{C}$ at time 0 . Equation (8) represents the data for group 3 animals acclimated to 18 or $26 \mathrm{C}$ for from 1 to 3 wk. The starting point for group 3 was animals which were held at $12 \mathrm{C}$ for 21 days in the presence of food. Therefore, the 144 observations obtained following storage at $T a 12 \mathrm{C}$ for 21 days in the presence of food were included in the data used to compile equation (8). In this case, half of the observations were considered to represent animals acclimated to $18 \mathrm{C}$ at time 0 and the other half, animals acclimated to $26 \mathrm{C}$ at time 0 .

The two equations have multiple correlation coefficients of .84 and .85 , so that they account for $84 \%$ and $85 \%$ of the variation of $L m$ in the data on which they are based.

THE INFLUENCE OF EXPOSURE TEMPERATURE

The effect of short-term $T e$ on the oxygen consumption of Ligia oceanica is shown for 10 fully fed, different-sized animals measured after 21 days' acclimation to $12 \mathrm{C}$ (fig. $7 a$ ) or $18 \mathrm{C}$ (fig. $7 b$ ). The most important general feature which is apparent is that, whereas the aerobic metabolism of animals acclimated to $12 \mathrm{C}$ declined after $30 \mathrm{C}$, that of animals acclimated to $18 \mathrm{C}$ declined only after $35 \mathrm{C}$. Warm acclimation apparently increases the heat tolerance of the organisms. It also involves more complex changes in the form of the rate:temperature curves which cannot be conveniently interpreted by mere examination of the raw data. Such changes are best illustrated by theoretical curves produced from the multipleregression equations and are introduced in a definite time sequence in figures 10 and 11. 
Figure 10 shows the curves generated from multiple-regression equation (6) for group 1 animals - that is, those collected from the shore in January 1973 and measured at a variety of exposure temperatures prior to laboratory acclimation. It may be regarded as the starting point from which the curves illustrated in figure 11 are derived. Figure 11 shows the theoretical curves relating $L m$ as a function of $T e$ for animals acclimated to $5,12,18$, and $26 \mathrm{C}$ for $1-3 \mathrm{wk}$. Continuous lines show the data for fed animals, while the broken lines show the corresponding curves for starved animals. The graphs also show the rate:temperature curves for a theoretical animal of $160 \mathrm{mg}$ dry wt ( $L d 2.2)$ and of $16 \mathrm{mg}$ dry wt ( $L d 1.2)$.

Clearly, after only $1 \mathrm{wk}$ at $T a 5 \mathrm{C}$ the curves for both starved and fed animals are essentially dependent upon temperature with a maximal rate occurring at approximately $30 \mathrm{C}$. Values for both starved and fed animals are similar, suggesting that laboratory starvation has little effect on aerobic metabolism at low $T a$ s. The curves for animals held for 13 days at $T a 5 \mathrm{C}$ are also generally similar to one another, although after 20 days the metabolism of the small starved Ligia of $16 \mathrm{mg}$ dry wt was suppressed, compared with that of fully fed specimens. This suppression seems likely to be due to the higher utilization of metabolic reserves by small animals and resembles results obtained on the shore crab Carcinus maenas (Marsden et al. 1973).

The curves for animals held at $T a$ $12 \mathrm{C}$ for between 8 and 21 days have some general similarities to those obtained for animals held at $5 \mathrm{C}$; the curves for both starved and fed animals are similar in level after only $1 \mathrm{wk}$ of storage but there is an increased suppression of the rate of small starved Ligia.
The changes noted in response to storage and starvation at 5 and $12 \mathrm{C}$ can be detected much earlier in animals held at 18 or $26 \mathrm{C}$. In both cases, the aerobic metabolism of small starved animals is suppressed, compared with large or well-fed animals after only $1 \mathrm{wk}$ of storage. The curves are also of a complex form, with a region of reduced temperature sensitivity over the range 20-30 C, much as we have noted in specimens of Littorina littorea collected directly from the shore in the summer (Newell and Roy 1973).

It can be concluded, therefore, that both time and acclimation temperature are important in determining the responses of the aerobic metabolism of $L$. oceanica to acute temperature change. In general, starvation effects make themselves felt first on smaller-sized animals after $3 \mathrm{wk}$ at $T a 5 \mathrm{C}, 2 \mathrm{wk}$ at Ta $12 \mathrm{C}$, and $1 \mathrm{wk}$ or less at temperatures above $T a 18 \mathrm{C}$. An increase in the upper limit of thermal tolerance is induced after 3 wk at $T a 12 \mathrm{C}, 2$ wk at Ta $18 \mathrm{C}$, and after 6 days or less at Ta $26 \mathrm{C}$. The influence of acclimation period itself appears to be rather variable at low Tas. The temperature beyond which a decline in aerobic metabolism occurs is more clearly related to $T a$ than to time. The average temperatures at which the metabolic rate reaches its maximum value after $1-3 \mathrm{wk}$ acclimation to $5,12,18$, and $26 \mathrm{C}$ are progressively higher (table 2). These values illustrate the increase in thermal tolerance which is associated with thermal acclimation in Ligia rather more clearly than in the estimates obtained from the simple regressions shown in figures 3-6 (see fig. 8).

A reduction in temperature coefficient for metabolism, with the development of a region of reduced temperature sensitivity over the middle part of the 
rate:temperature curve, appears consistently in fed Ligia held at $T a 5 \mathrm{C}$ or Ta $12 \mathrm{C}$ for 21 days and in fed specimens held for only 8 days at $T a 18 \mathrm{C}$, but it occurs in both starved and fed groups at high Tas of $26 \mathrm{C}$. A reduction of metabolic reserves induced by starvation does not in itself appear to be a primary cause of the reduced temperature sensitivity noted in the rate:temperature curves for this animal (see Newell $1973 a, 1973 b)$, although there is some indication that it may be involved in a modification of rate:temperature relationships at low $T a$.

These features of the rate: temperature curves are summarized in table 3 , from

TABLE 2

TEMPERATURE AT WHICH MAXIMUM METABOLIC RATE OCCURS IN FED AND STARVED "LIGIA OCEANICA" ACCLIMATED TO 5, 12, 18, AND $26 \mathrm{C}$

\begin{tabular}{|c|c|c|}
\hline \multirow[b]{2}{*}{$T a \mathrm{C}$} & \multicolumn{2}{|c|}{$\begin{array}{c}\text { Temperature at Which } \\
\text { Maximum Metabolic } \\
\text { Rate Occurs }\end{array}$} \\
\hline & Fed C & Starved C \\
\hline 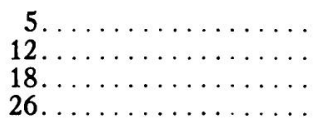 & $\begin{array}{l}27.6 \\
28.2 \\
33.1 \\
33.4\end{array}$ & $\begin{array}{l}29.5 \\
29.8 \\
29.9 \\
32.4\end{array}$ \\
\hline
\end{tabular}

NoTE.-Data represent the average for grouns acclimated for 1-3 wk at each temperature. Based on the 24 multiple-regression equations illustrated in fig. 10. which the shift of the region of temperature insensitivity from 15 to $25 \mathrm{C}$ at low Tas to 20-35 C at high Tas shows more clearly than in the simple regressions illustrated in figures 3-6 (see also fig. 8).

The discussion above is based on the equations evaluated within 25 relatively small subgroups of data according to equation (6) which closely fit the actual data (fig. 7). A more synthetic view of the results and a smoothing of most of the discontinuities of figure 11 into partial-regression lines results from a graphical representation of equations (7) and (8). Figure 12, based on equation (7), and figure 13 , based on equation (8), were constructed according to the graphical procedures used to build figure 9.

These figures should be viewed as four imaginary buildings which symbolize four four-dimensional cross sections through the multidimensional space described by equation (7). The bent ground floors of the buildings represent the $L m: T e$ curves of 16-mg dry-weight animals $(L d 1.2)$ at various acclimation times between 0 and 21 days. The bent roofs have the same meaning for $160-\mathrm{mg}$ dry-weight animals ( $L d 2.2)$. A middle floor representing the medium-sized animals ( $L d 1.7$ ) was omitted to avoid clutter. The pair of curvilinear lines

TABLE 3

INTERVAL OF REDUCED TEMPERATURE COEFFICIENT IN THE METABOLISM OF "LIGIA OCEANICA" ACCLIMATED FOR 1-3 WK AT $5,12,18$, AND $26 \mathrm{C}$

\begin{tabular}{|c|c|c|c|c|c|c|}
\hline \multirow[b]{3}{*}{$T a \mathrm{C}$} & \multicolumn{6}{|c|}{ Zone of Reduced-Temperature Coefficient (C) } \\
\hline & \multicolumn{3}{|c|}{$\begin{array}{l}\text { Fed } \\
\text { (wk) }\end{array}$} & \multicolumn{3}{|c|}{$\begin{array}{l}\text { Starved } \\
(\mathbf{w k})\end{array}$} \\
\hline & 1 & 2 & 3 & 1 & 2 & 3 \\
\hline $\begin{array}{l}5 \ldots \ldots \ldots \\
12 \ldots \ldots \ldots \\
18 \ldots \ldots \\
26 \ldots \ldots\end{array}$ & $\begin{array}{l}15-25 \\
15-25 \\
10-25 \\
20-35\end{array}$ & $\begin{array}{l}15-25 \\
20-30 \\
20-35 \\
20-35\end{array}$ & $\begin{array}{l}20-30 \\
20-30 \\
20-35 \\
20-35\end{array}$ & $\begin{array}{l}15-25 \\
10-20 \\
20-30 \\
20-30\end{array}$ & $\begin{array}{l}15-25 \\
20-30 \\
20-30 \\
20-25\end{array}$ & $\begin{array}{l}15-30 \\
20-30 \\
20-35\end{array}$ \\
\hline
\end{tabular}

Note.-Based on fig. 8 for medium-sized animals of $50 \mathrm{mg}$ dry wt ( $L d 1.7)$. 
appearing to stand in the back of the buildings, where they are connected with the points for $F d 0$ or $S d 0$, correspond to the $L m: T e$ curves for group 1 animals (fig. 12) or for group 2 animals after 3 -wk feeding at $12 \mathrm{C}$ (fig. 13). Together with the $L d$ lines with which they are connected, they appear as the transparent rear wall of each building and represent the three-dimensional $L d: T e: L m$ relationship of the animals which serves as the common starting point (see fig. 1).

The $L m: T e$ curves of animals acclimated to 5 or $12 \mathrm{C}$ have one peak located between 25 and $30 \mathrm{C}$ in large or small fed animals. In the starved small animals the peak of the $L m: T e$ curves is slightly over $30 \mathrm{C}$. In the starved large animals the peak stands close to $25 \mathrm{C}$ at the beginning of acclimation but is shifted close to $30 \mathrm{C}$ at the end

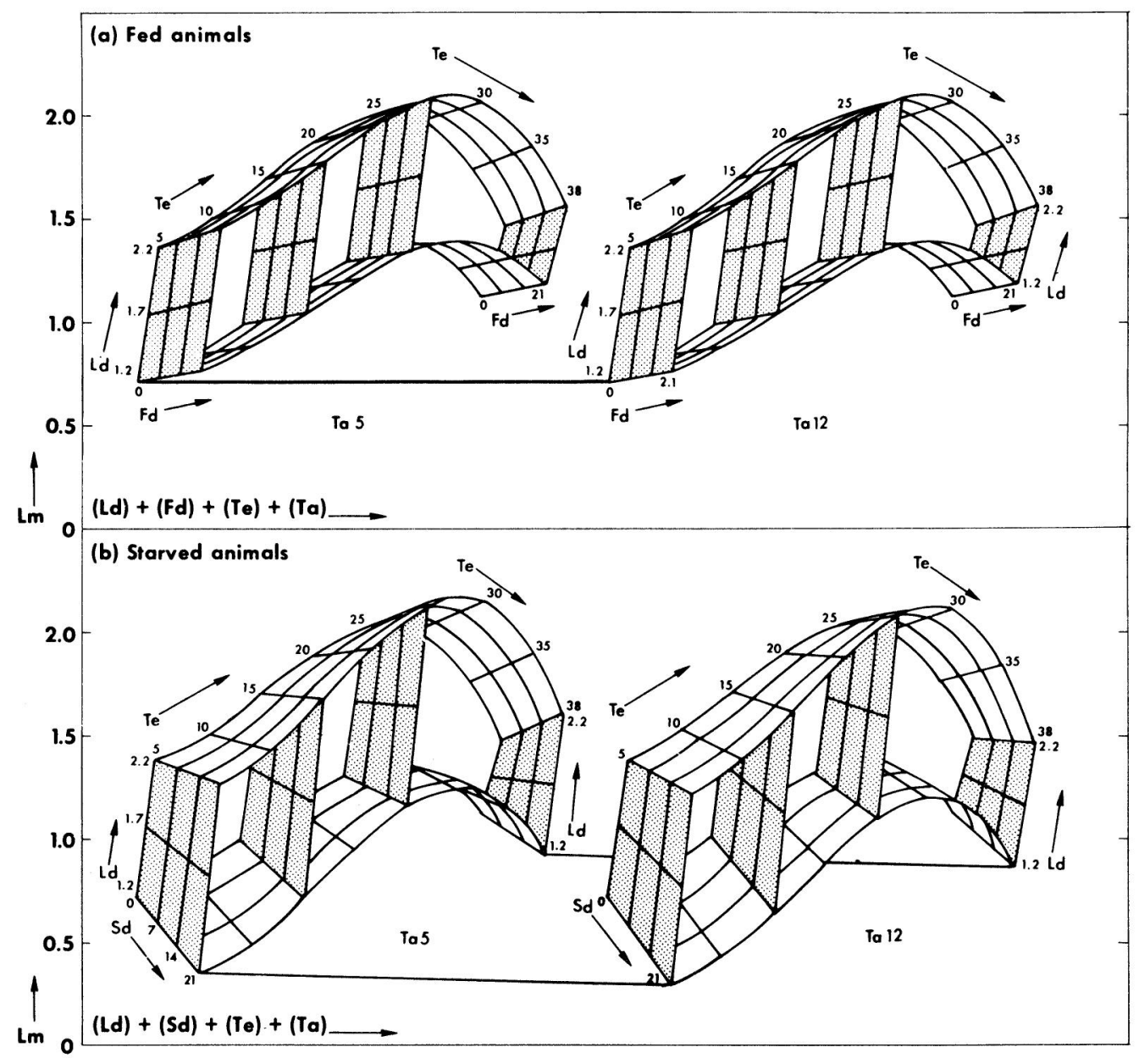

FIG. 12.-Multidimensional representation of eq. (7). a, Effect of $L d, T e$, and $F d$ on $L m$ of Ligia oceanica acclimated to 5 or 12 C. $b$, Effect of $L d, T e$, and $S d$ on $L m$. The graphical scales were set to optimize the visual appreciation of the effects of $T e, F d$, and $S d$. The $P l$ is fixed at $25 \%$ of total dry weight. The ( $L d)$, $(F d),(S d),(T e)$, and $(T a)$ are graphical values of $L d, F d, S d, T e$, and $T a$ added to obtain the abscissa value of each intersection or reference points of the graphs. 
of 21 days. A feature common to the four diagrams is that the ascending and descending portions of the $L m: T e$ curves for large animals are steeper than they are for small animals, so that homologous $L m: T e$ curves are not parallel to each other. This difference in slopes did not appear in figures 10 and 11 because the limited number of observations and different values of $T e$ within each of the 25 subgroups of data did not permit statistical evaluation of $L m: T e$ together with $L d$. Thus only pairs of parallel
$L m: T e$ curves could be shown. Although slope differences were apparent from one pair to another (fig. 11), those differences were smoothed when $L d, T e$, and $S d$ were combined (fig. 12).

Following acclimation to 18 or $26 \mathrm{C}$, the $L m: T e$ curves have two peaks (fig. 13). The interval between the main peak at 30-35 $\mathrm{C}$ and the secondary peak at $15-20 \mathrm{C}$ has a low temperature coefficient associated with temperature insensitivity. The main peak of $L m$ shifted toward a higher $T e$ value in

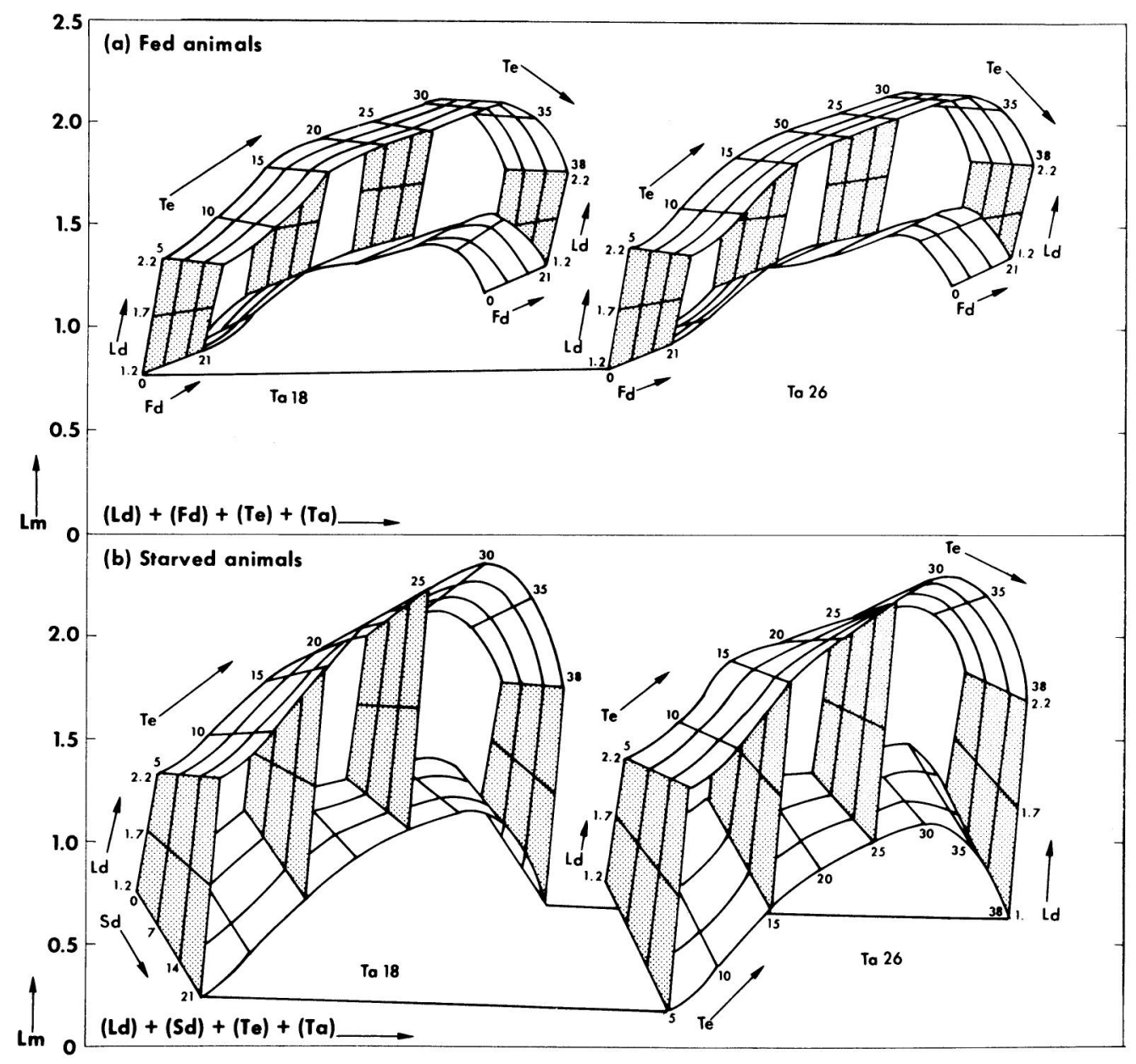

Fig. 13.-Multidimensional representation of eq. (8). Effect of $L d, T e$, and $F d$ (graph $a$ ) or $S d$ (graph $b$ ) on $\mathrm{Lm}$ in Ligia oceanica acclimated to 18 or $26 \mathrm{C}$ after previously being fed and acclimated to $12 \mathrm{C}$ for 21 days. Graphical scales as in fig. 12. 
large starved animals over the 21 days. Also, as in animals acclimated to 5 or $12 \mathrm{C}$, the ascending and descending portions of the $L m: T e$ curves are steeper for large animals than for small animals.

THE INFLUENCE OF NUTRITIONAL LEVEL

The influence of nutritional level on oxygen consumption in $L$. oceanica is clearly illustrated by equations (7) and (8) (table 1) and figures 12 and 13, which describe the metabolism of animals acclimated to 5 or $12 \mathrm{C}$ (group 2) and 18 or $26 \mathrm{C}$ (group 3), respectively. In equations (7) and (8), $F d$ and $S d$ were included as rectilinear semilogarithmic partial regressions shown in figures 12 and 13 as a collection of $F d: L m$ and $S d: L m$ lines. Although generally the combination of fed-acclimation increased aerobic metabolism and starvedacclimation reduced metabolism, inspection of figures 12 and 13 shows that the effect of starvation is not the mere opposite of the effect of feeding. This relationship is evident in the percentage of increase or decrease in aerobic metabolism following 3 -wk acclimation.

The effect of 3 -wk acclimation on the metabolism of fed animals varies with body size but not with $T e$ or $T a$ (eqq. [7] and [8], table 1). Among group 2 animals (fig. 12), the metabolic rate of 16-mg animals ( $L d 1.2$ ) increased 13\% and that of $160-\mathrm{mg}$ animals ( $L d$. 2.2) increased $26 \%$. Among group 3 animals (fig. 13), the metabolic rate of $16-\mathrm{mg}$ animals increased $35 \%$ but that of 160 mg animals decreased $7 \%$.

The effect of starvation on metabolism is more important than that of feeding. After 3-wk acclimation, metabolism of starved animals varied with body size, $T a$, and $T e$ (table 4 ). The reduction of metabolism of $16-\mathrm{mg}$ animals was greater at each higher $\mathrm{Ta}$. The maximum reduc-
TABLE 4

PERCENTAGE OF MODIFICATION OF AEROBIC METABOLISM OF "LIGIA OCEANICA" INDUCED BY 3-WK STARVATION ACCORDING TO BODY SIZE, $T a$, AND $T e$

\begin{tabular}{crrrr}
\hline & & \multicolumn{3}{c}{$T e$} \\
\cline { 3 - 5 } $\begin{array}{c}\text { Body Size } \\
\text { (mg Dry Wt })\end{array}$ & $\begin{array}{r}T a \\
(\mathrm{C})\end{array}$ & $\begin{array}{c}5 \mathrm{C} \\
(\%)\end{array}$ & $\begin{array}{c}25 \mathrm{C} \\
(\%)\end{array}$ & $\begin{array}{c}38 \mathrm{C} \\
(\%)\end{array}$ \\
\hline $16 \ldots \ldots \ldots$ & 5 & -59 & -30 & -42 \\
& 12 & -62 & -40 & -50 \\
& 18 & -69 & -44 & -69 \\
& 26 & -79 & -58 & -73 \\
& 5 & -23 & +30 & +8 \\
& 12 & -32 & +14 & -5 \\
& 18 & -6 & +68 & -5 \\
& 26 & -29 & +27 & -29 \\
\hline
\end{tabular}

Note.-Based on eqq. (7) and (8).

tion of $79 \%$ occurred at $T a=26 \mathrm{C}$ and $T e=5 \mathrm{C}$. Metabolism was reduced somewhat at intermediate temperatures (e.g., Te $25 \mathrm{C}$ ) than at either end of the range of $T e$. Aerobic metabolism was reduced less in 160-mg animals; the maximum was $32 \%$ at $T a=12 \mathrm{C}$ and $T e=5 \mathrm{C}$. Possibly large animals used lesc of their metabolic reserves. Moreover, the effect of starvation in the large animals was reversed at $T e$ s close to those causing maximum metabolic rate, and starvation was associated with an increase, rather than a reduction, of metabolic rate. This inversion of the effect of $S d$ in large starved animals is linked (figs. 12 and 13) with the previously noted shift to the right of the peak of the $L m$ : Te curves. This inversion emphasizes the interactions observed among $L d, S d$, and $T e$.

These results thus emphasize that the effects of starvation on oxygen consumption in $L$. oceanica are controlled not only by body size and duration of starvation, as noted in Carcinus (Marsden et al. 1973), but also by the temperature at which the isopods are held without food. 
THE INFLUENCE OF ACCLIMATION TEMPERATURE AND ACCLIMATION PERIOD

The principal effect of thermal acclimation on the aerobic metabolism of L. oceanica is to raise thermal tolerance, or the point beyond which a decline occurs, from approximately $27.5 \mathrm{C}$ to $33 \mathrm{C}$ (table 2). The influence of $T a$ and acclimation period on the level of aerobic metabolism, as opposed to effects on heat tolerance, are, however, best compared by means of equations (7) and (8) (table 1). The effect of acclimation period cannot be distinguished from the effects of either feeding period or starving period.

Figure 14 shows the effect of $T a$ after
21 days' acclimation period on the metabolic rate of fed or starved Ligia at selected $T e$. This figure is the equivalent of another series of three-dimensional cross sections through the multidimensional space described by equations (7) and (8). At each higher $T a$, metabolic rate of fed animals generally increases and that of starved animals decreases, so that the effect of $T a$ as such is not definitely distinguishable from that of feeding or starving for 21 days. The only exceptions would be in large animals ( $L d 2.2, F d 21$ ) tested at $T e$ of 5 or $25 \mathrm{C}$ whose average metabolic rate after acclimation to 18 or $26 \mathrm{C}$ (group 3) appears lower than that after acclimation to 5

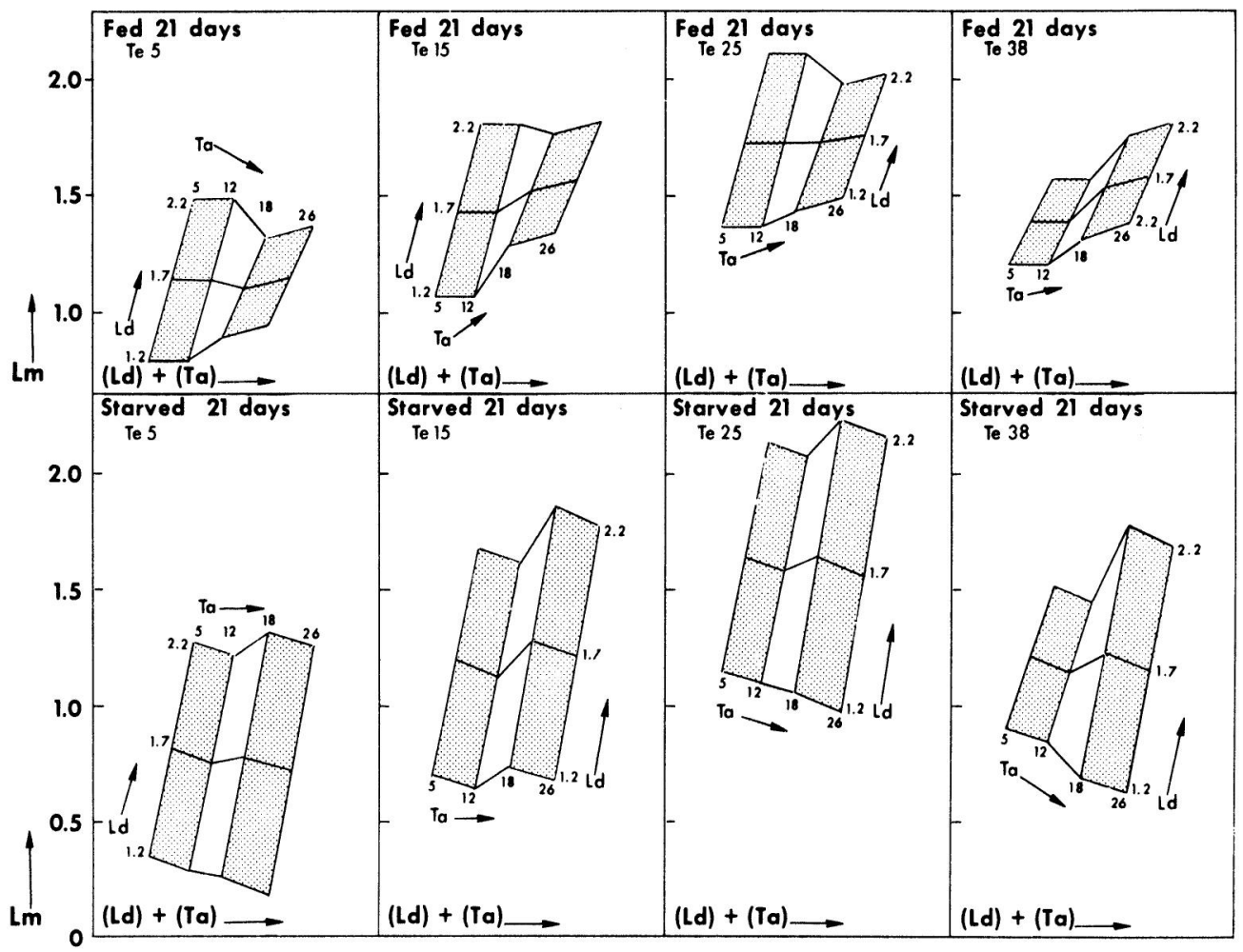

FIG. 14.-Three-dimensional representations of eqq. (7) and (8) showing the effect of $L d$ and $T a$ on $L m$ of Ligia oceanica fed or starved for 21 days and tested at selected Tes. Lipid content held constant at $25 \%$ of total dry weight. Graphical scales were set to optimize the visual appreciation of the effect of $T a$. The left-hand shaded panel in each diagram is based on eq. (7); the right-hand shaded panel is based on eq. (8). The connecting nonshaded area corresponds to the joint influence of an additional 21 days' storage in the laboratory and an increase of $T a$ from 12 to $18 \mathrm{C}$. 
or $12 \mathrm{C}$ (group 2). However, since this exception is complicated by the longer laboratory storage of group 3 animals and is not supported by metabolic rates at $T e$ of 15 and $38 \mathrm{C}$, where the slope for $T a$, between $T a 5$ and $26 \mathrm{C}$, is either horizontal or ascending, we conclude that the effect of $T a$ in Ligia fed ad libitum does not comply with the wellknown reduction in metabolic rate which follows warm acclimation in many invertebrates (for review, see Prosser 1973). In this respect the results resemble those for the isopod L. beaudiana (Wieser 1972) and for Porcellio scaber (Newell et al. 1974).

Thus the principal effect of laboratory storage on the level of metabolism in $L$. oceanica appears to be related to the influence of time and temperature on the level of metabolic reserves, rather than to acclimatory responses to temperature itself. Attempts to correlate the effects of starvation time with the $P l$ of Ligia were, however, not satisfactory. Although a significant correlation was obtained between the level of aerobic metabolism and $\mathrm{Pl}$, the reduction of other reserves may be important in inducing the reduced levels of oxygen consumption following starvation, or there may be a threshold level of lipid below which metabolism is reduced.

THE INFLUENCE OF BODY SIZE

The 181 simple regressions of $L m$ as a function of $L d$ have slopes that vary widely from -0.48 to +2.01 . Among these, 128 (or $70.7 \%$ ) have a value not significantly different from 0.72 at the $5 \%$ level of probability, a value which is similar to the slope for the interspecific regressions of Hemmingsen (1960) and that of 0.726 reported for Ligia by Ellenby (1951). Thirty-two of the regression lines (or 17.7\%) have a slope which is significantly lower than 0.72 , while 21 (or 11.6\%) have a slope which is significantly higher than 0.72 .

It is obvious that any environmental or endogenous factor which has an unequal effect on large and small animals will modify the slope of the relation between metabolic rate and body size. There are many examples in which the temperature sensitivity of large and small individuals is different, so that $T e$ and, to a lesser extent, $T a$ fall into this category. But additional factors such as nutritional level in the case of Ligia and Carcinus (Marsden et al. 1973) interact with body size and modify its influence on metabolic rate.

Although equations (7) and (8) do not completely explain the pattern of variation of the $L m: L d$ relation in $L$. oceanica, they do show that part of this variation is associated with the variations of $T e, F d$, and $S d$. In figure $9 f$, the graphical scales were chosen to permit a visualization of the variation of the slopes of the $L m: L d$ lines as associated with different values of $S d$ and $T e$ in equation (8). However, a more complete mathematical estimation of the slope variation for $L d$ is obtained if the terms containing $L d$ are isolated from the rest of each equation. The regression coefficient of $L d$ then varies as follows:

According to equation (7), for Ligia acclimated to 5 or $12 \mathrm{C}$ for $0-21$ days, the regression coefficient of $L d$ varies according to the following equation:

$$
\begin{array}{r}
Y=.6254+.0003312 T e^{2}-.3843 \times 10^{-6} \\
T e^{4}+.005004 F d+.01458 S d .
\end{array}
$$

The corresponding equation based on equation (8), for Ligia acclimated to 18 or $26 \mathrm{C}$ and stored in the laboratory for 21-42 days, is

$$
\begin{aligned}
& Y=.5847+.2215 \times 10^{-4} T e^{3}-.2215 \\
& \times 10^{-6} T e^{4}-.007544 F d+.02285 S d .(10)
\end{aligned}
$$


TABLE 5

VARIATION OF THE REGRESSION COEFFICIENT OF $L d$ ON $L m$ IN "LIGIA OCEANICA," AS PREDICTED BY MULTIPLE-REGRESSION EQUATIONS (9) AND (10)

\begin{tabular}{|c|c|c|c|c|c|}
\hline \multirow[b]{2}{*}{ Condition of Accuimation } & \multicolumn{5}{|c|}{$T e \mathrm{C}$} \\
\hline & 10 & 20 & 30 & 35 & 38 \\
\hline $\begin{array}{l}\text { Fed } 7 \text { days at } 5 \text { or } 12 \mathrm{C} \ldots \ldots \ldots \ldots \\
\text { Fed } 14 \text { days at } 5 \text { or } 12 \mathrm{C} \ldots \ldots \ldots \ldots \ldots \\
\text { Fed } 21 \text { days at } 5 \text { or } 12 \mathrm{C} \ldots \ldots \ldots \ldots\end{array}$ & $\begin{array}{l}0.690 \\
0.725 \\
0.760\end{array}$ & $\begin{array}{l}0.731 \\
0.766 \\
0.801\end{array}$ & $\begin{array}{l}0.647 \\
0.682 \\
0.717\end{array}$ & $\begin{array}{l}0.489 \\
0.524 \\
0.559\end{array}$ & $\begin{array}{l}0.337 \\
0.372 \\
0.407\end{array}$ \\
\hline $\begin{array}{l}\text { Starved } 7 \text { days at } 5 \text { or } 12 \mathrm{C} \ldots \ldots \ldots \\
\text { Starved } 14 \text { days at } 5 \text { or } 12 \mathrm{C} \ldots \ldots \ldots \\
\text { Starved } 21 \text { days at } 5 \text { or } 12 \mathrm{C} \ldots \ldots \ldots\end{array}$ & $\begin{array}{l}0.757 \\
0.859 \\
0.961\end{array}$ & $\begin{array}{l}0.798 \\
0.900 \\
1.002\end{array}$ & $\begin{array}{l}0.714 \\
0.816 \\
0.918\end{array}$ & $\begin{array}{l}0.556 \\
0.658 \\
0.760\end{array}$ & $\begin{array}{l}0.404 \\
0.506 \\
0.608\end{array}$ \\
\hline $\begin{array}{l}\text { Fed } 7 \text { days at } 18 \text { or } 26 C \ldots \ldots \ldots \ldots \\
\text { Fed } 14 \text { days at } 18 \text { or } 26 \mathrm{C} \ldots \ldots \ldots \ldots \\
\text { Fed } 21 \text { days at } 18 \text { or } 26 \mathrm{C} \ldots \ldots \ldots \ldots\end{array}$ & $\begin{array}{l}0.548 \\
0.495 \\
0.443\end{array}$ & $\begin{array}{l}0.617 \\
0.564 \\
0.512\end{array}$ & $\begin{array}{l}0.665 \\
0.613 \\
0.560\end{array}$ & $\begin{array}{l}0.621 \\
0.568 \\
0.515\end{array}$ & $\begin{array}{l}0.551 \\
0.499 \\
0.446\end{array}$ \\
\hline $\begin{array}{l}\text { Starved } 7 \text { days at } 18 \text { or } 26 \mathrm{C} \ldots \ldots \ldots \\
\text { Starved } 14 \text { days at } 18 \text { or } 26 \mathrm{C} \ldots \ldots \ldots \\
\text { Starved } 21 \text { days at } 18 \text { or } 26 \mathrm{C} \ldots \ldots \ldots\end{array}$ & $\begin{array}{l}0.761 \\
0.921 \\
1.081\end{array}$ & $\begin{array}{l}0.830 \\
0.990 \\
1.150\end{array}$ & $\begin{array}{l}0.978 \\
1.038 \\
1.198\end{array}$ & $\begin{array}{l}0.834 \\
0.994 \\
1.154\end{array}$ & $\begin{array}{l}0.764 \\
0.924 \\
1.084\end{array}$ \\
\hline
\end{tabular}

The regression coefficients of $L d$, as predicted from these equations, ranged from 0.33 to 1.20 (table 5). In $78.5 \%$ of the cases, the predicted slopes obtained from equations (9) and (10) fall within the fiducial interval of the value obtained for the 181 simple regressions determined within the original small units at the $5 \%$ probability level. If the fiducial intervals are evaluated at the $1 \%$ level, the percentage of conformity becomes 86.2. The values for the regression coefficient for $\log$ metabolic rate as a function of $\mathrm{Lm}$ are plotted against $\mathrm{Te}$ in figure 15, which shows the values predicted from equations (9) and (10) for starved or fed Ligia held for 21 days at 5 or $12 \mathrm{C}$ and at 18 or $26 \mathrm{C}$.

Two main features are apparent from inspection of table 5 and figure 15. First, the regression coefficient for starved Ligia is much greater than that for well-fed animals. This difference is not unexpected, because the marked suppression of aerobic metabolism of small animals relative to large ones following starvation has already been noted above. Further, the enhanced effect of such starvation on the oxygen consumption of animals held at 18 or $26 \mathrm{C}$, compared with those at 5 or $12 \mathrm{C}$, would account for the differences between these two groups in the regression coefficients for starved animals shown in figure 10 .

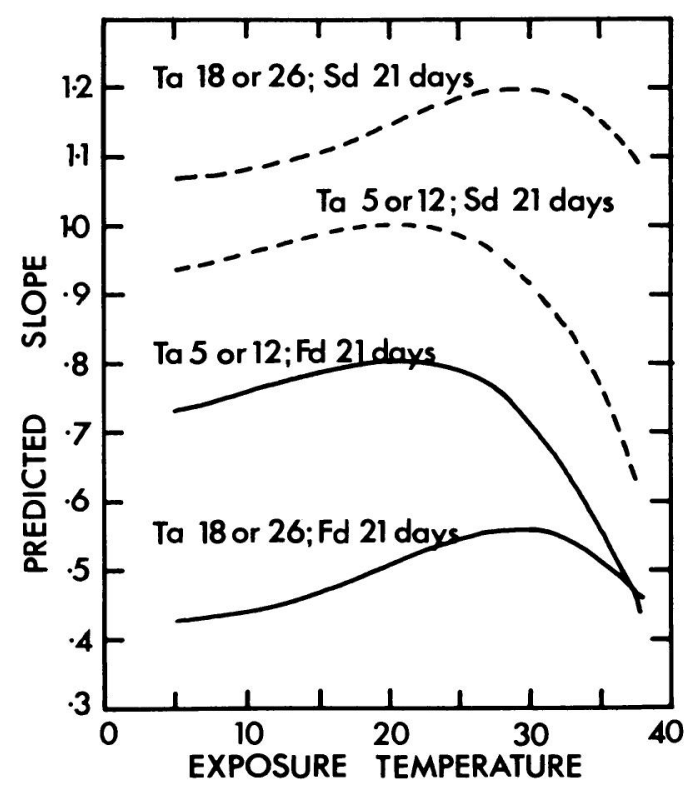

FIG. 15.--Variation in the slope of the regression lines relating $L m$ to $L d$ in Ligia oceanica at different $T e s$. Continuous lines for animals fed during acclimation and broken lines for starved specimens. Based on eqq. (9) and (10). 
The second feature which is of importance in figure 15 is that the variation of the regression coefficient of $L d$ with $T e$ is curvilinear in L. oceanica. As can be seen also in equations (7) and (8), the slope of the lines relating $L m$ to $L d$ increases with $T e$ at low temperatures and then decreases at higher temperatures. This curvilinearity may account for an apparent anomaly in the only two other organisms which we have subjected to the same kind of statistical analysis. In the slug Arion circumscriptus (Roy 1969), measurements were made at only four different values of $T e$ from 12.5 to $30 \mathrm{C}$. In this animal the slope of the regression relating metabolic rate to body size decreased with increasing Tes, rather like the descending portion of the curves for $L$. oceanica (fig. 15). This trend also occurs in the data for Megascolex (Saroja 1959). Uca (Vernberg 1959), and several barnacles (Barnes and Barnes 1969). On the other hand, in the data for Littorina the values for the slope of the regression lines relating $L m$ to $L d$ increased with increasing $T e$ (Newell and Roy 1973), much as reported for several other invertebrates (Rao and Bullock 1954; Newell 1976). In this case there were 16 different values of $T e$ from 1 to 37.5 $\mathrm{C}$; the lower Tes below $25 \mathrm{C}$ were particularly well represented in the data, where they accounted for $75 \%$ of all the observations. The large representation of lower $T e$ could explain why the pattern of variation of the slope of the regressions for Littorina is similar in form to those obtained in the lower part of the temperature range in figure 15.

Further data on a variety of other invertebrates will be required to show whether the variation in slope of the regression lines relating $L m$ to $L d$ noted in Arion, Littorina, and Ligia occurs in other animals. However, it seems likely that, if a sufficient range of temperatures is studied and if other factors such as starvation are included in the analyses, the different thresholds of sensitivity of large and small animals to these factors will be reflected in a regular variation of the regression coefficient with $T e$.

\section{CONCLUSIONS}

Our results suggest that the rate of aerial oxygen consumption of the isopod Ligia oceanica is affected by a wide variety of environmental and endogenous factors, even in the absence of locomotory activity. The principal environmental factors include short-term $T e$ and the period of starvation, although the temperature at which this occurs is also of importance in controlling the level of aerobic metabolism. Attempts to quantify these starvation effects in terms of the $P l$ in the dried tissues of Ligia yielded rather low correlations. Possibly starvation effects are induced by the reduction of some other metabolic substrate, by the reduction of lipid to a threshold level, by the lack of an opportunity to feed, or by some combination of these. Endogenous factors affecting the oxygen consumption of quiescent animals include, above all, body size. Undoubtedly the level of overt activity would, as in many other invertebrates (for review, see Newell 1973b), be important in determining the level of oxygen consumption in Ligia, but activity was not accounted for in the present study.

Several crustaceans, including the isopod Porcellio scaber (Newell et al. 1974), the crabs Cancer pagurus and Maia squinado (Aldrich 1975), and the crayfish Orconectes nais (Rice and Armitage 1974), exhibit rates of oxygen consumption elevated above predicted rates in the absence of overt activity. These elevated rates have been ascribed to the 
effects of initial "excitation" during transfer into a respirometer and may reflect muscular activity which cannot be readily observed. While we have not taken this effect systematically into account in our experiments, probably the initial equilibration period and the large number of data pooled to generate the multiple-regression equations minimized the residual effects of initial excitation in the predicted curves.

Of the environmental factors, it would be true to say that, in general, the rate of oxygen consumption of $L$. oceanica is dependent upon temperature, much as in L. beaudiana (Wieser 1972), the isopod $P$. scaber (Newell et al. 1974), and in many other invertebrates. This pattern is especially true of specimens held at a low $T a$ of $5 \mathrm{C}$; but, following storage at higher $T a \mathrm{~s}$ of 12,18 , or $26 \mathrm{C}$, the rate:temperature curve for oxygen consumption becomes definitely sigmoid, with a region of reduced temperature sensitivity over the middle part of the range of thermal tolerance (see table 3 ). This response to warm acclimation thus resembles that obtained during seasonal acclimation in the winkle Littorina littorea. Somewhat to our surprise, however, the period and temperature of acclimation has little obvious effect on the level of oxygen consumption of $L$. oceanica, much as has been reported for $L$. beaudiana (Wieser 1972) and $P$. scaber (Newell et al. 1974). In this respect, the oxygen consumption of these isopods does not show a "typical" suppression following warm acclimation, as reported in many invertebrates (see Bullock 1955; Prosser 1973). Whether this lack of a clear acclimatory response is general in isopods is not yet established (see Edney 1964a, 1964b). There is, however, an increase in the heat tolerance from 27.5 to $33.4 \mathrm{C}$ following thermal acclimation (table 2), which re- sembles the results for terrestrial isopods cited by Edney (1964a). The rate at which these changes in the form and temperature relationships of aerobic metabolism are induced is dependent upon $T a$ and occurs after 3 wk storage at $12 \mathrm{C}, 2 \mathrm{wk}$ at $18 \mathrm{C}$, and less than $1 \mathrm{wk}$ at $26 \mathrm{C}$.

The principal endogenous factor which we have systematically taken into account in this study is body size, although we also analyzed the total lipid content in an effort to define the effects of starvation. As in the case of many other organisms, the slope of the regression line relating $L m$ to $L d$ varies around a value which is similar to that obtained in interspecific studies (see Zeuthen 1953; Hemmingsen 1960). However, in Ligia the responses of the large- and small-sized animals to factors such as starvation time and $T e$ are different, particularly at the extremes of the range of temperature tolerance. Such differences may partly explain the widely different values reported in the literature for the regression coefficients in even quite closely related species obtained under different experimental conditions and underline the importance of body size in an interpretation of the effects of environmental factors on invertebrate metabolism.

\section{SUMMARY}

1. Measurements were made of aerobic metabolism $\left(\mathrm{mm}^{3} \mathrm{O}_{2} / \mathrm{h}\right)$ of the supralittoral isopod Ligia oceanica in relation to body size (dry weight in milligrams) and exposure temperature following laboratory storage under controlled conditions.

2. Measurements of six independent variables, log dry body weight $(L d)$, exposure temperature $(T e)$, acclimation temperature $(T a)$, feeding period in days $(F d)$, starving period in days $(S d)$, 
and percentage of lipids $(P l)$ were related to the dependent variable, log metabolic rate $(\mathrm{Lm})$.

3. A multiple-regression equation was derived in which the statistical significance of the effects of the independent variables on $L m$ could be arranged in the following order: $T e, L d, S d, F d, T a$, $P l$.

4. The method had the important advantage that complex relationships between the independent variables and metabolism which could not be easily interpreted by mere examination of the 3,130 individual observations constituting the raw data could be quantified.

5. The metabolism of Ligia could not be conveniently expressed in terms of one multiple-regression equation without loss of accuracy when reapplied to the individual experimental data. Instead, two equations were derived. The first accounted for $84 \%$ of the variation of $L m$ in animals acclimated to 5 or $12 \mathrm{C}$. The second accounted for $85 \%$ of the variation of $L m$ in animals acclimated to $18 \mathrm{C}$ or $26 \mathrm{C}$.

6. The multiple-regression equations were then used in a predictive fashion to quantify the effects of $T e$, nutritional level, $T a$, acclimation period, and body size on oxygen consumption in Ligia. Multidimensional graphics were used to demonstrate visually the complex interactions of the independent variables.

7. The rate:temperature curve for aerobic metabolism was sigmoid, with a region of reduced temperature sensitivity at intermediate $T e s$, much as in other invertebrates.

8. Two main responses occurred following thermal acclimation. First, the temperature at which the maximum metabolic rate occurred was shifted from $27.6 \mathrm{C}$ in fed animals acclimated to $5 \mathrm{C}$ to $28.2 \mathrm{C}$ in those acclimated to $12 \mathrm{C}$; $33.1 \mathrm{C}$ in those acclimated to $18 \mathrm{C}$, and $33.4 \mathrm{C}$ in those acclimated to $26 \mathrm{C}$. Second, there was a shift in the region of reduced temperature sensitivity from 15-25 C at low Tas to 20-35 C at high Tas.

9. Thermal acclimation has little effect on the level of metabolism of well-fed Ligia. The principal effect of laboratory storage is related to the influence of temperature and time on the level of metabolic reserves, rather than to acclimatory responses to temperature itself.

10. The effects of starvation on oxygen consumption in Ligia are controlled not only by body size and duration of starvation but also by the temperature at which the isopods are held without food. Small animals show a suppression of metabolism sooner than large ones at each $T a$, and high $T a$ s enhance the onset and magnitude of such effects.

11. The influence of body size on metabolism in Ligia varied according to $T e$ and period of starvation. The significance of these results in relation to studies on other invertebrates was discussed.

\section{LITERATURE CITED}

AldRICH, J. C. 1975. On the oxygen consumption of the crabs Cancer pagurus (L.) and Maia squinado (Herbst.). Comp. Biochem. Physiol. 50A : 223-228.

ANSELL, A. D. 1973. Changes in oxygen consumption, heart rate and ventilation accompanying starvation in the decapod Cancer pagurus. Neth. J. Sea Res. 7:455-475.

Armitage, K. B. 1962. Temperature and oxygen consumption of Orchomonella chilensis (Heller) (Amphipoda: Gammaroidea). Biol. Bull. 123: 225-232.

Armitage, K. B., R. C. Newell, and A. Roy. 1976. Factors affecting the lipid content of the isopod Ligia oceanica (forthcoming).

BARNEs, H. and M. BARnEs. 1969. Seasonal changes in the acutely determined oxygen consumption and effect of temperature for three 
common cirripedes, Balanus balanoides (L.), B. balanus (L.) and Chthamalus stellatus (Poli). J. Exp. Marine Biol. Ecol. 4:36-50.

Bayne, B. L., R. J. Thompson, and J. Widdows. 1973. Some effects of temperature and food on the rate of oxygen consumption by Mytilus edulis L. Pages 181-193 in W. Wieser, ed. Effects of temperature on ectothermic organisms. Springer-Verlag, Heidelberg.

Bullock, T. H. 1955. Compensation for temperature in the metabolism and activity of poikilotherms. Biol. Rev. 30:311-342.

Dehnel, P. A. 1958. Effect of photoperiod on the oxygen consumption of two species of intertidal crabs. Nature $181: 1415-1417$.

Duncan, A. 1966. The oxygen consumption of Potamopyrgusjenkinsi (Smith) (Prosobranchiata) in different temperatures and salinities. Verhandlungen Int. Vereinigung Limnol. 16:1739-1751.

Edney, E. B. 1964a. Acclimation to temperature in terrestrial isopods. I. Lethal temperatures. Physiol. Zoöl. 37:364-377.

- 1964b. Acclimation to temperature in terrestrial isopods. II. Heart rate and standard metabolic rate. Physiol. Zoöl. 37:378-394.

Effroymson, M. A. 1960. Multiple regression analysis. Pages 19-203 in A. RALston and H. S. WILF, eds. Mathematical methods for digital computers. Vol. 1. Wiley, New York.

Ellenby, C. 1951. Body size in relation to oxygen consumption and pleopod beat in Ligia oceanica L. J. Exp. Biol. 28:492-507.

Ellenby, C., and D. A. Evans. 1956. On the relative importance of body weight and surface area measurements for the prediction of the level of oxygen consumption of Ligia oceanica L. and prepupae of Drosophila melanogaster Meig. J. Exp. Biol. 33: 134-141.

Finney, D. J. 1952. Probit analysis. Cambridge University Press, Cambridge.

Fredette, V., C. Planté, and A. Roy. 1967. Numerical data concerning the sensitivity of anaerobic bacteria to oxygen. J. Bacteriol. 93:2012-2017.

Hagerman, L. 1970. The oxygen consumption of Crangon vulgaris (Fabricius) (Crustacea, Natantia) in relation to salinity. Ophelia $7: 283-292$.

Halcrow, K., and C. M. Boyd. 1967. The oxygen consumption and swimming activity of the amphipod Gammarus oceanicus at different temperatures. Comp. Biochem. Physiol. 23:233242.

Hemmingsen, A. M. 1960. Energy metabolism as related to body size and respiratory surfaces and its evolution. Rep. Steno Hosp. Copenhagen 9:7-110.

Klekowski, R. Z., and A. Duncan. 1966. The oxygen consumption in saline water of young Potamopyrgus jenkinsi (Smith) (Prosobranchiata). Verhandlungen Int. Vereinigung Limnol. 16: 1753-1760.
McFarland, W. N., and P. E. Pickens. 1965. The effects of season, temperature, and salinity on standard and active oxygen consumption of the grass shrimp Palaemonetes vulgaris (Say). Can. J. Zool. 43:571-583.

McLaren, I. A. 1963. Effects of temperature on growth of zooplankton, and the adaptive value of vertical migration. J. Fisheries Res. Board. Can. 20:685-727.

Mangum, C. P., and W. Van Winkle. 1973. Responses of aquatic invertebrates to declining oxygen conditions. Amer. Zool. 13:529-541.

Marsden, I. D., R. C. Newell, and M. AhsanulLAH. 1973. The effect of starvation on the metabolism of the shore crab, Carcinus maenas. Comp. Biochem. Physiol. 45A : 195-213.

Newell, R. C. 1973a. Environmental factors affecting the acclimatory responses of ectotherms. Pages 151-164 in W. Wieser, ed. Effects of temperature on ectothermic organisms. Springer-Verlag, Heidelberg.

$\rightarrow-1973 b$. Factors affecting the respiration of intertidal invertebrates. Amer. Zool. 13:513-528.

_- 1975. Factors controlling metabolic capacity adaptation in marine invertebrates. Pages 111-127 in F. J. Vernberg, ed. Physiological ecology of estuarine organisms. University of South Carolina Press, Columbia.

- 1976. Adaptations to intertidal life. In Adaptation to environment: studies on the physiology of marine animals. Butterworth, London (in press).

Newell, R. C., and B. L. Bayne. 1973. A review on temperature and metabolic acclimation in intertidal marine invertebrates. Neth. J. Sea Res. 7:421-433.

Newell, R. C., and A. Roy. 1973. A statistical model relating the oxygen consumption of a mollusk (Littorina littorea) to activity, body size, and environmental conditions. Physiol. Zoöl. 46:253-275.

Newell, R. C., W. Wieser, and V. I. Pye. 1974. Factors affecting oxygen consumption in the woodlouse Porcellio scaber Latr. Oecologia 16: 31-51.

Prosser, C. L. 1973. Comparative animal physiology. Saunders, Philadelphia.

RAO, K. P. 1958. Oxygen consumption as a function of size and salinity in Metapenaeus monoceros Fab. from marine and brackish-water environments. J. Exp. Biol. 35:307-313.

RAO, K. P., and T. H. Bullock. 1954. $Q_{10}$ as a function of size and habitat temperature in poikilotherms. Amer. Natur. 87:33-43.

Remmert, H. 1967. Physiologisch-ökologische Experiments an Ligia oceanica (Isopoda). Z. Morphol. Okologie Tiere 59:33-41.

Rice, P. R., and K. B. Armitage. 1974. The effect of photoperiod an oxygen consumption of the crayfish Orconectes nais (Faxon). Comp. Biochem. Physiol. 47A : 261-270. 